Revista de Estudios Histórico-Jurídicos

[Sección historia del derecho europeo]

XXXIX (Valparaíso, Chile, 2017)

[pp. 141 - 170]

\title{
LA EXCLUSIÓN DEL PRINCIPIO MANDATUM MORTE DISSOLVITUR EN EL DERECHO ROMANO Y EN LA TRADICIÓN JURÍDICA ESPAÑOLA*
}

[Exclusion of the mandatum morte dissolvitur principle in Roman Law and the Spanish legal tradition]

\author{
Ma Elena Sánchez Collado** \\ Universidad Rey Juan Carlos, España
}

\section{RESUMEN}

En el presente trabajo analizamos la exclusión del principio mandatum morte dissolvitur en el derecho romano y en la tradición jurídica española hasta el Código Civil de 1889. Encontramos excepciones a la aplicabilidad de este principio, por una parte, en el instituto del mandatum post mortem, que aunque discutido en el derecho clásico alcanzaría cierto reconocimiento más claro en el derecho justinianeo y que acabaría diluyéndose a partir del derecho de la recepción; y por otra, en otras hipótesis plenamente acogidas en el derecho de la recepción y en el derecho civil español vigente, en que el contrato de mandato subsiste después de fallecido el mandante o el mandatario.

Palabras clave

Contrato de mandato - Negocios post mortem - Muerte del mandante Muerte del mandatario - Extinción de las obligaciones.

\begin{abstract}
This work analyses the exclusion of the mandatum morte dissolvitur principle in Roman law and in the Spanish legal tradition until the 1889 Civil Code. On one hand, we found exceptions to the enforceability of this principle in the institute of the mandatum post mortem which, in spite of being discussed in classic law, attained some degree of recognition in Justinian law, and subsequently vanishes as from the doctrine of jurisprudential reception; and on the other, in other fully accepted hypotheses by the legal reception and the current Spanish law, in which the mandate agreement remains after the death of the principal or agent.

KeYwords

Mandate agreement - Post mortem business - Death of the principal - Death of the representative - Extinction of the obligations.
\end{abstract}

RECibIDO el 28 de abril y ACEPTADO el 23 de junio de 2017

* El presente trabajo se realiza en el marco del proyecto de I+D+i con referencia DER201453497-p, financiado por el Ministerio de Economía y Competitividad.

" Profesora Titular de derecho romano. Universidad Rey Juan Carlos (URJC). Paseo de los Artilleros s/n. 28032 - Vicálvaro - Madrid. Correo electrónico: mariaelena.sanchez@urjc.es. 


\section{EL PRINCIPIO MANDATUM MORTE DISSOLVITUR}

Antes de abordar el examen de las hipótesis de exclusión del principio objeto de nuestro estudio, intentaremos una primera aproximación a la formulación del mismo.

Es este un principio general que encontramos en los siguientes textos romanos:

Gai 3,160: "Item si adhuc integro mandato mors alterutrius alicuius interveniat, id est vel eius, qui mandarit, vel eius, qui mandatum susceperit, solvitur mandatum [...]".

I. 3,26(27),10: "Item si adhuc integro mandato mors alterutrius interveniat, id est vel eius qui mandaverit, vel eius qui mandatum susceperit, solvitur mandatum [...]".

Paulo D. 17,1,26 pr.: "Inter causas omittendi mandati etiam mors mandatoris est: nam mandatum solvitur morte [...]".

La máxima que acogen los preceptos mencionados determina que el contrato de mandato se extingue por la muerte tanto del mandante como del mandatario, por tratarse de un contrato de confianza de carácter personalísimo. En efecto, la resolución del mandato se produce al dejar de tener utilidad para las partes por la muerte de cualquiera de ellas, al quedar privado este contrato del fundamento para su subsistencia ${ }^{1}$. La regla mandatum morte dissolvitur inspiraría entre otros cuerpos legales el contenido del artículo 2003 del Código Civil francés de 1804², del 2163 del Código Civil chileno de $1855^{3}$, del 1732 del Código Civil español de $1889^{4}$, del Art. 1722 Código Civil italiano de $1942^{5}$, así como del artículo 1329 del vigente Código Civil y Comercial de la Nación argentina del $2014^{6}$.

Sin embargo, ya desde el derecho romano, se introducirían excepciones a este principio en los propios textos precitados, así como en Paulo D. 46,3,108 y C. $4,35,15^{7}$. Como veremos, en el derecho romano la exclusión de la regla que nos

1 Torrent, Armando, s.v. mandatum morte resolvitur, en Diccionario de derecho romano (Madrid, 2005), p. 677.

2 El artículo 2003 del Código Civil francés en su redacción actual tras de su modificación por una ley de 12 de mayo de 2009 dispone: "Le mandat finit: [...] Par la mort, la tutelle des majeurs ou la déconfiture, soit du mandant, soit du mandataire." En su redacción originaria el precepto establecía: "Le mandat finit: [...] Par la mort naturelle ou civile, la tutelle des majeurs ou la déconfiture, soit du mandant, soit du mandataire". La vigente redacción obedece a la supresión de la institución de la muerte civil por virtud de una ley de 31 de mayo de 1854.

${ }^{3}$ El vigente artículo 2163 del Código Civil chileno establece: "El mandato termina: $5 .^{\circ}$ Por la muerte del mandante o del mandatario".

${ }^{4}$ El artículo 1732 del Código Civil español de 1889 también dispone como veremos en profundidad más adelante: "El mandato se acaba: 3. ${ }^{\circ}$ Por muerte, declaración de prodigalidad o por concurso o insolvencia del mandante o del mandatario".

${ }^{5}$ El Art. 1722 del Código Civil italiano establece: "Il mandato si estingue: 4) per la morte, l'interdizione o l'inabilitazione del mandante o del mandatario".

${ }^{6}$ El artículo 1329 del Código Civil y Comercial de la Nación aprobado por la Ley 26.994 y promulgado según decreto 1795/2014 dispone: "El mandato se extingue: e) por la muerte $o$ incapacidad del mandante o del mandatario”. El artículo 1963 del precedente Código Civil argentino de 1869 establecía en cambio: "El mandato se acaba: 3 - Por el fallecimiento del mandante o del mandatario".

7 El texto de Paulo D. 46,3,108 lo examinaremos más adelante con mayor profundidad y respecto del C. 4, 35, 15 este dispone: "Mandatum re integra domini morte finitur. * DIOCL. 
ocupa podía deberse en ocasiones a la admisibilidad del instituto del mandatum post mortem, en otras, a la circunstancia de fallecer el mandante ignorándolo el mandatario, o bien a la hipótesis de que no se tratase de un integro mandato, por haberse iniciado ya la ejecución del contrato, de suerte que hubiesen de persistir la obligatio y la actio mandati.

Vacario considera clara y explícitamente el mandatum post mortem mandatoris como una excepción que excluye la aplicación de la máxima mandatum morte dissolvitur, cuya finalidad primordial consistiría en realizar alguna gestión en interés del heredero del mandante. El romanista y canonista italiano alude a esta excepción en los siguientes términos: "si mandatum conceptum sit post mortem, durat post mortem".

Son numerosos los cuerpos normativos en los que se excluye la aplicación de la regla mandatum morte dissolvitur y entre otros, podríamos citar los siguientes: el artículo 2008 del Código Civil francés de 1804 cuya redacción originaria se mantiene ${ }^{9}$, los artículos 2168, 2169 y 2170 del Código Civil chileno de $1855^{10}$, el artículo 280 del Código de Comercio español de $1885^{11}$, el artículo 1738 del Código Civil español de $1889^{12}$; $\$ 672$ y $\$ 673$ del BGB de $1900^{13}$, los artículos

ET MAXIM. AA. ET CC. AURELIO PRECARIO ATHENAEO. *<A 294 D. XVII K. MAI. CC. CONSS.>.

${ }^{8}$ Vacario, Roger, Liber Pauperum, p. 255, cit. por Domingo, Rafael (coord.) - OrTega, Javier - Rodríguez-Antolín, Beatriz - Zambrana, Nicolás, Principios de derecho global. 1000 reglas y aforismos jurídicos comentados (2a edición, Cizur Menor, 2006), pp. 265-266.

9 El artículo 2008 del Código Civil francés dispone: "Si le mandataire ignore la mort du mandant ou l'une des autres causes qui font cesser le mandat, ce qu'il a fait dans cette ignorance est valide".

${ }^{10}$ El artículo 2168 del Código Civil chileno de 1855 establece: "Sabida la muerte del mandante, cesará el mandatario en sus funciones; pero si de suspenderlas se sigue perjuicio a los herederos del mandante, será obligado a finalizar la gestión principiada". El contenido de este precepto se complementa con el artículo 2169: "No se extingue por la muerte del mandante el mandato destinado a ejecutarse después de ella. Los herederos suceden en este caso en los derechos y obligaciones del mandante". Y finalmente con el 2170: "Los herederos del mandatario que fueren hábiles para la administración de sus bienes, darán aviso inmediato de su fallecimiento al mandante, y harán en favor de éste lo que puedan y las circunstancias exijan: la omisión a este respecto los hará responsables de los perjuicios. A igual responsabilidad estarán sujetos los albaceas, los tutores y curadores y todos aquellos que sucedan en la administración de los bienes del mandatario que ha fallecido o se ha hecho incapaz".

11 El artículo 280 del Código de Comercio español conserva su redacción originaria y dispone: "Por muerte del comisionista o su inhabilitación se rescindirá el contrato; pero por muerte o inhabilitación del comitente no se rescindirá, aunque pueden revocarlo sus representantes".

12 El artículo 1738 del Código Civil español contempla la misma excepción que la precitada del artículo 2008 del Código Civil francés y la estudiaremos con mayor profundidad al abordar el estudio de esta cuestión en el derecho civil español.

${ }^{13}$ El $\$ 672$ establece: "Der Auftrag erlischt im Zweifel nicht durch den Tod oder den Eintritt der Geschäftsunfähigkeit des Auftraggebers. Erlischt der Auftrag, so hat der Beauftragte, wenn mit dem Aufschub Gefahr verbunden ist, die Besorgung des übertragenen Geschäfts fortzusetzen, bis der Erbe oder der gesetzliche Vertreter des Auftraggebers anderweit Fürsorge treffen kann; der Auftrag gilt insoweit als fortbestehend". Y añade el \$ 673: "Der Auftrag erlischt im Zweifel durch den Tod des Beauftragten. Erlischt der Auftrag, so hat der Erbe des Beauftragten den Tod dem Auftraggeber unverzüglich anzuzeigen und, wenn mit dem Aufschub Gefahr verbunden ist, die Besorgung des 
1722 4) en su inciso final, 1728 y 1729 del Código Civil italiano de $1942^{14}$ y el artículo 1333 del actual Código Civil y Comercial de la Nación argentina del $2014^{15}$.

\section{EXCEPCIONES A ESTE PRINCIPIO EN EL DERECHO ROMANO}

\section{El mandatum post mortem}

Podríamos definir el mandatum post mortem como aquel mandato cuyo objeto hubiese de ejecutarse después de la muerte del mandante o del mandatario ${ }^{16}$. Se trataba en definitiva de un contrato de mandato consistente en realizar algún encargo, bien después del fallecimiento del mandante o del mandatario, de suerte

übertragenen Geschäfts fortzusetzen, bis der Auftraggeber anderweit Fürsorge treffen kann; der Auftrag gilt insoweit als fortbestehend". De los preceptos mencionados se puede inferir que, como regla general, por muerte del mandante el mandato continúa en favor de los herederos, mientras que como norma generalizada por muerte del mandatario el contrato se extingue.

${ }_{14} \mathrm{El}$ artículo 1722. 4) en su inciso final dispone: "Tuttavia il mandato che ha per oggetto il compimento di atti relativi all'esercizio di un'impresa non si estingue, se l'esercizio dell'impresa è continuato, salvo il diritto di recesso delle parti o degli eredi". El artículo 1728 indica que "Quando il mandato si estingue per morte o per incapacità sopravvenuta del mandante, il mandatario che ha iniziato l'esecuzione deve continuarla, se vi è pericolo nel ritardo. Quando il mandato si estingue per morte o per sopravvenuta incapacità del mandatario, i suoi eredi ovvero colui che lo rappresenta $o$ lo assiste, se hanno conoscenza del mandato, devono avvertire prontamente il mandante e prendere intanto nell'interesse di questo i provvedimenti richiesti dalle circostanze". Y finalmente el artículo 1729 señala que "Gli atti che il mandatario ha compiuti prima di conoscere l'estinzione del mandato sono validi nei confronti del mandante o dei suoi eredi".

15 El Artículo 1333 del vigente Código Civil y Comercial de la Nación establece: "Producida la muerte o incapacidad del mandatario, sus herederos, representantes o asistentes que tengan conocimiento del mandato deben dar pronto aviso al mandante y tomar en interés de éste las medidas que sean requeridas por las circunstancias. Si se produce la muerte o incapacidad del mandante, el mandatario debe ejecutar los actos de conservación si hay peligro en la demora, excepto instrucciones expresas en contrario de los herederos o representantes". Con anterioridad, el Código Civil argentino de 1869 trataba esta materia con una mayor extensión en los siguientes preceptos: artículo 1964: "Para cesar el mandato en relación al mandatario y a los terceros con quienes ha contratado, es necesario que ellos hayan sabido o podido saber la cesación del mandato"; artículo 1965: "No será obligatorio al mandante, ni a sus herederos, o representantes, todo lo que se hiciere con ciencia o ignorancia imputable de la cesación del mandato"; artículo 1966: "Será obligatorio al mandante, a sus herederos o representantes, en relación al mandatario, todo cuanto éste hiciere ignorando, sin culpa la cesación del mandato, aunque hubiese contratado con terceros que de ella tuvieren conocimiento"; artículo 1967: "En relación a terceros, cuando ignorando sin culpa la cesación del mandato, hubieren contratado con el mandatario, el contrato será obligatorio para el mandante, sus herederos y representantes, salvo sus derechos contra el mandatario, si éste sabia la cesación del mandato"; artículo 1968: "Es libre a los terceros obligar o no al mandante, sus herederos o representantes, por los contratos que hubieren hecho con el mandatario, ignorando la cesación del mandato; mas el mandante, sus herederos o representantes, no podrán prevalerse de esa ignorancia para obligarlos por lo que se hizo después de la cesación del mandato"; y artículo 1969: "No obstante la cesación del mandato, es obligación del mandatario, de sus herederos, o representantes de sus herederos incapaces, continuar por si o por otros los negocios comenzados que no admiten demora, hasta que el mandante, sus herederos o representantes dispongan sobre ellos, bajo pena de responder por perjuicio que de su omisión resultare".

16 Torrent, Armando, cit. (n. 1), pp. 677-678. 
que la ejecución correspondía realizarla a los herederos, circunstancia que implicaba una clara excepción a la regla general que determinaba la extinción del contrato de mandato por muerte de cualquiera de los contratantes.

En la doctrina romanística se planteó el problema dogmático que suscita la naturaleza híbrida de esta institución, que prima facie aparece como un negocio inter vivos, pero que al propio tiempo puede presentarse como un cauce apropiado para la conclusión de negocios mortis causa ${ }^{17}$. Sobre este particular, como ya puso de relieve Jordano Barea ${ }^{18}$, ambas calificaciones no son antitéticas, sino compatibles. En el mismo sentido indica José María Ribas Alba, que no existe en realidad una incompatibilidad entre los dos tipos, porque operan en ámbitos bien distintos ${ }^{19}$.

Se ha cuestionado por otra parte polémica en la romanística acerca de la admisibilidad del instituto del mandatum post mortem en el derecho clásico, por cuanto que los fragmentos de los juristas clásicos que nos han sido transmitidos a través del Digesto reflejan la problemática que suscitaba la precitada institución en el período mencionado. En época clásica se cuestionaba la admisibilidad de este instituto por estimarse que vulneraba tanto el principio mandatum morte dissolvitur como la regla "ab heredis persona obligatio incipere non potest", que determinaba que una obligación no pudiera tener su inicio en la persona del heredero (Gai $3,100 ; 3,158)^{20}$. Numerosos estudiosos del derecho romano han observado la

${ }^{17}$ De estos problemas dogmáticos se ha ocupado RaBIE, Hamed A., L'acte juridique post mortem en droit romain: Validité et fonction, (Milano, 1955), pp. 31-32, quien distingue entre los actos post mortem, cuya exigibilidad se remite al dies mortis, y los actos mortis causa en los que la muerte es un elemento esencial del propio negocio. En efecto, indica el A.: "Un trait caractérise l'acte post mortem: l'accomplissement d'une ou de plusieurs obligations est référé à la mort de l'une des deux parties contractantes [...] L'acte mortis causa est un acte juridique qu'on ne peut concevoir sans que, pour son existence, la mort soit considérée comme un élément essentiel; autrement, c'est un acte juridique inter vivos. Dans l'acte post mortem, nous sommes en présence d'un négoce, où seule l'exigibilité d'une des obligations est soumise au dies mortis". Esta opinión no ha recibido unánime aceptación en la doctrina. En contra se han manifestado Di PAOLA, Santi [cfr. su recensión realizada a la obra de Rabie: L'atto giuridico post mortem en Labeo, 1 (1955), pp. 342 ss. y la respuesta de Rabie a Di Paola en L'atto giuridico post mortem, Labeo, 3 (1957), pp. 92 ss.], así como Gómez-Carbajo de Viedma, Fernando José, Mandatum post mortem, en Revista de la Facultad de Derecho Universidad Complutense, (1989-1990), p. 130, y RiBas Alba, José María, Mandatum post mortem, en Seminarios Complutenses de Derecho Romano, 14 (2002), p. 70. En nuestra opinión, discrepamos de la drástica consideración de que el acto mortis causa sea un acto jurídico que no pueda concebirse sin que la muerte se considere como un elemento esencial para su existencia, so pena de que, en la hipótesis contraria, nos encontremos ante un acto jurídico inter vivos.

${ }^{18}$ JoRDAno BAREA, Juan Bautista, Teoría general del testamento, en Anales de la Universidad Hispalense, 24 (1963), pp. 61-93.

${ }_{19}$ En efecto, señala Ribas Alba, cit. (n. 17), pp. 69-70, que, observada la distinción con detalle, se constata que no existe en realidad una incompatibilidad entre los dos tipos: un acto es inter vivos cuando se realiza entre dos sujetos capaces y legitimados para vincularse en una concreta relación jurídica (bilateralidad subjetiva); produce sus efectos inmediatamente salvo que se añada algún elemento accidental. Por su parte, el negocio se califica como mortis causa exclusivamente por el tipo de función que el sujeto (o los sujetos si es bilateral) proyectan con su actividad: regular una situación provocada por la muerte del sujeto (o de uno de ellos).

${ }^{20}$ Cfr. TORRENT, Armando, cit. (n. 1), pp. 677-678, en que se indica que esta regla que tenía su aplicación especial con relación a la stipulatio y al contrato de mandato implicaba la 
existencia de una antinomia entre la firme declaración de nulidad del mandatum post mortem mandatoris que se contempla en D. 46,3,108, y algunos fragmentos del Digesto tales como D. 17,1,12,17; D. 17,1,13 y probablemente también D. $17,1,27,1$, en los que parece reconocerse la validez de esta figura.

Según Gayo el principio general que inspiró a los prudentes en el tratamiento y solución de los problemas derivados del m.p.m. se encuentra contemplado en el fragmento 158 del libro 3 de sus Instituciones: "Item si quis quid post mortem meam faciendum mihi mandet, inutile mandatum est, quia generaliter placuit ab heredis persona obligationem incipere non posse".

Con excepción de Pernice, la doctrina se ha inclinado por estimar que el texto precitado solo alude al mandatum post mortem mandatarii, pero no al mandatum post mortem mandatoris ${ }^{21}$; en cambio, al hablar Gayo en I. 3,100 de la stipulatio post mortem, en realidad alude tanto a la referida a la muerte del estipulante como a la del promitente, declarando la nulidad de ambas ${ }^{22}$, inspirándose para ello en una regla muy similar a la que se contempla en I. 3,158: "nam inelegans esse uisum est ab heredis persona incipere obligationem”. Es, sin embargo, numeroso el sector de la romanística que estima que el mandatum post mortem mandatoris era nulo también en la época clásica, aunque no se mencione en el fragmento 3,158 del manuscrito de Verona. Para Bonfante ${ }^{23}$ y Arangio Ruiz ${ }^{24}$ dicha nulidad se deriva de la misma regla que conlleva la del mandatum post mortem mandatarii. Vasa$1 \mathrm{li}^{25}$, Di Marzo ${ }^{26}$, Perozzi ${ }^{27}$ y Solazzi ${ }^{28}$ consideran que la nulidad del mandatum post mortem mandatoris no es sino una consecuencia de la regla mandatum morte solvitur $^{29}$. Sin embargo, partiendo del silencio de Gayo 3,158 y sobre la base de

nulidad del negocio, cuando la obligatio, tanto del lado activo como pasivo traía su inicio en la persona de uno de los herederos. Por eso se estimaba nulo el mandato que hubiera de cumplirse después de la muerte del mandante o del mandatario.

${ }^{21}$ Alfred Pernice, en efecto, no distingue entre uno y otro supuesto, y estima nula cualquier hipótesis de mandatum post mortem. Cfr. Labeo: Römisches Privatrecht im ersten Jahrhundert der Kaiserzeit, III, (Halle, 1892; reimp. Aalen, 1963), 1, p. 129.

${ }^{22}$ Gai. III, 100: "Denique inutilis est talis stipulatio, si quis ita dari stipuletur: POST MORTEM MEAM DARI SPONDES? uel ita: POST MORTEM TVAM DARI SPONDES? ualet autem, si quis ita dari stipuletur: CVM MORIAR, DARI SPONDES?uel ita: CVM MORIERIS, DARI SPONDES? id est, ut in nouissimum uitae tempus stipulatoris aut promissoris obligatio conferatur: nam inelegans esse uisum est ab heredis persona incipere obligationem. rursum ita stipulari non possumus: PRIDIE QVAM MORIAR, aut PRIDIE QVAM MORIERIS, DARI SPONDES? quia non potest aliter intellegi 'pridie quam aliquis morietur', quam si mors secuta sit; rursus morte secuta in praeteritum reducitur stipulatio et quodam modo talis est: HEREDI MEO, DARI SPONDES? quae sane inutilis est".

${ }^{23}$ Bonfante, Pietro, Mandatum post mortem, en Scritti giuridici varii (Turín, 1926), III, pp. 262 ss.

${ }^{24}$ ARAngio Ruiz, Vincenzo, Il mandato in diritto romano (1949, reimp. Napoli, 1965), pp. 157-158.

${ }_{25}$ VASAlli, Filippo E., Di talune clausole con riferimento al "dies mortis" nel legato e nella stipulazione (Firenze, 1910), pp. 20-21; 28-29; y 32.

${ }^{26}$ Di Marzo, Salvatore, Sul mandato post mortem, en Scritti Ferrini, 1 (1947), pp. 233 -238.

${ }^{27}$ Perozzi, Silvio, Istituzioni di diritto romano (2a ed., Milano, 1928), II, p. 310, n. 2.

${ }^{28}$ SolazzI, Siro, Sull'obbligazzione a termine iniziale, en Iura, 1 (1950), pp. 50 ss.

${ }^{29}$ También se manifiestan en contra de la validez de la figura VAN Oven, Julius Christiaan, 
la interpretación de diversos textos del Digesto ${ }^{30}$, así como de las Instituciones de Gayo $^{31}$, algunos autores mantienen la validez general del mandatum post mortem mandatoris en el derecho clásico como es el caso de Lotmar $^{32}$, de Sanfilippo ${ }^{33}$ y de Rabie $^{34}$. También hay autores que como Vazny ${ }^{35}$ reconocen la validez del mandatum post mortem mandatoris heredi, sin reconocérsela en cambio al mandatum post mortem mandatoris alteri, en aplicación de la regla mandatum morte dissolvitur.

Desde la perspectiva de nuestra doctrina, para Gómez-Carbajo ${ }^{36}$ parece deducirse de la interpretación de los textos que han llegado hasta nosotros que el mandatum post mortem mandatoris sería admitido en algunos casos, y rechazado en otros, reconociéndose en aquellos supuestos en que no resulte vulnerada la regla general mencionada en Gayo 3,158, para fundamentar la nulidad del mandatum post mortem mandatarii: “obligatio ab heredis persona incipere non potest". Y añade el A. que podría concluirse del estudio de las fuentes, que la misma regla que Gayo aplicó en 3,158 para justificar la nulidad del mandatum post mortem mandatarii, puede servir de fundamento según la jurisprudencia romana, para discernir en cada caso la validez o nulidad del mandatum post mortem mandatoris. Para el A, la reglamentación del mandatum post mortem presenta diferencias sustanciales en el derecho clásico romano y en la compilación justinianea ${ }^{37}$. El derecho justinianeo derogaría los principios que implicaban un obstáculo para la validez de esta institución, admitiéndose en C. 8,37(38),11 cualquier modalidad de contratos post mortem compositos ${ }^{38}$, orientación que es también la seguida en una constitución del año 531 recogida en C. 4,11,139.

Gaius 3.158: mandatum post mortem mandantis, en Symbolae Raphaeli Taubenschlag, 1 (1956), pp. 529 ss.; HARDER, Manfred, Zum transmortalen und postmortalen Auftrag nach römischen und geltendem Recht, en Sein und Werden im Recht. Festgabe für Ulrich von Lübtow zum, 70 (Berlin, 1970), pp. 515-536 y WaTSON, Alan, Contract of mandate in Roman law (Oxford, 1961), p. 147.

${ }^{30}$ D. $17,1,12,17 ; 17,1,13 ; 17,1,27,1 ; y$ 46,3,108.

${ }^{31}$ Gai. 3,117.

32 Lotmar, Philipp, Marc Aurels Erlass über die Freilassungsauflage, en ZSS. 33 (1912), p. 320 n. 1.

${ }^{33}$ SAnfilippo, Cesare, Mandatum post mortem, en Studi Solazzi (1948), pp. 554 y ss.

${ }^{34}$ Rabie, Hamed A., "D. 46,3,108», en Studi Arangio Ruiz (Napoli, 1953), IV. pp. 263 ss.

${ }_{35}$ VÀnY, Jan, Il problema generale dei contratti a favore di terzi nel Diritto Romano, en BIDR., 40 (1932), pp. 79 ss.

${ }^{36}$ Gómez-Carbajo de Viedma, Fernando José, cit. (n. 17), p. 136.

${ }^{37}$ Ibíd., p. 129.

${ }^{38}$ CJ. 8,37,11: Imperator Justinianus A. Mennae P.P: "Scrupulosam inquisitionem, utrum post mortem, an cum morietur vel pridie quam morietur stipulatus sit aliquis vel in testamento legati vel fideicommissi nomine aliquid dereliquerit, penitus amputantes omnia, quae vel in quocumque contractu stipulati vel pacti sunt contrahentes, vel testator in suo testamento disposuit, etiamsi post mortem vel pridie quam morietur scripta esse noscuntur, nibilo minus pro tenore contractus vel testamenti valere praecipimus". * Iust. A. Menae pp. ${ }^{*}<\mathrm{a} 528 \mathrm{~d}$. iii id. dec. Constantinopoli dn. Iustiniano pp. A. ii cons.>”.

${ }^{39}$ CJ. 4,11,1 pr.: Imperator Justinianus A. Ioanni P.P: "Cum et stipulationes et legata et alios contractus post mortem compositos antiquitas quidem respuebat, nos autem pro communi hominum utilitate recepimus, consentaneum erat etiam illam regulam, qua vetustas utebatur, more humano emendare. 1. Ab heredibus enim incipere actiones vel contra heredes veteres non concedebant contemplatione stipulationum ceterarumque causarum post mortem conceptarum. 2. Sed nobis necesse 
La posición opuesta es la defendida por José María Ribas Alba, para quien el mandatum post mortem existió indudablemente en el derecho romano clásico como lo demuestra el examen de las fuentes ${ }^{40}$ y estima que las dos constituciones mencionadas que habitualmente se citan como modificativas de la hipotética ineficacia del mandato post mortem, en realidad nada tienen que ver con la figura que nos ocupa ${ }^{41}$.

Examinaremos a continuación algunos textos que la doctrina ha considerado especialmente ilustrativos en lo que concierne a la institución que nos ocupa:

1) El primero de ellos es D. 17,1,12,17 (Ulp. 31 ad ed.): "Idem Marcellus scribit, si, ut post mortem sibi monumentum fieret, quis mandavit, heres eius poterit mandati agere. Illum vero qui mandatum suscepit, si sua pecunia fecit, puto agere mandati, si non ita ei mandatum est, ut sua pecunia faceret monumentum. Potuit enim agere etiam cum eo qui mandavit, ut sibi pecuniam daret, ad faciendum, maxime si iam quaedam ad faciendum paravit".

El texto del D. 17,1,12,17 ha representado uno de los firmes baluartes para quienes mantienen la validez del mandatum post mortem mandatoris en el derecho clásico. Los defensores de su nulidad en cambio se inclinarían por afirmar que los compiladores habrían suprimido un non inicial reconociendo de este modo la acción al heredero del mandante, contra el parecer originario de Marcelo para quien el heredero del mandante (non) poterit mandati agere.

En relación al texto precitado se ha suscitado una polémica que se polariza en la utilización del término vero, para introducir el parecer de Ulpiano sobre las acciones que corresponden al mandatario -Illum vero qui mandatum suscepit-, y que en apariencia se contrapone a la opinión inicial de Marcelo en lo concerniente a la acción que corresponde al heredero del mandante ${ }^{42}$. Tal vez en este punto sea acertada la opinión de Sanfilippo ${ }^{43}$, quien interpretando este texto indica que la oposición que determina el vero consiste en que al heredero del mandante se le concede siempre acción contra el mandatario, mientras que al mandatario solo se le reconoce en ciertos casos.

Indica Gómez-Carbajo ${ }^{44}$ que en un mandato como el contemplado en esta

est, ne prioris vitii materiam relinquamus, et ipsam regulam e medio tollere, ut liceat et ab heredibus et contra heredes incipere actiones et obligationes, ne propter nimiam subtilitatem verborum latitudo voluntatis contrahentium impediatur. <a $531 \mathrm{~d}$. xv k. nov. constantinopoli post consulatum Lampadii et Orestae vv. cc.>”. También se contempla una tendencia permisiva frente a las anteriores prohibiciones en I. 3,19,13: "Post mortem suam dari sibi nemo stipulari poterat, non magis quam post eius mortem a quo stipulabatur. ac ne is qui in alicuius potestate est post mortem eius stipulari poterat, quia patris vel domini voce loqui videtur. sed et si quis ita stipuletur, PRIDIE QUAM MORIAR vel PRIDIE QUAM MORIERIS DARI? inutilis erat stipulatio. sed cum, ut iam dictum est, ex consensu contrahentium stipulationes valent, placuit nobis etiam in hunc iuris articulum necessariam inducere emendationem, ut, sive post mortem sive pridie quam morietur stipulator sive promissor, stipulatio concepta est, valeat stipulatio".

${ }^{40}$ Ribas Alba, José María, cit. (n. 17), p. 99.

${ }^{41}$ Ibíd., p. 100 n. 151.

${ }^{42}$ Con base en el carácter adversativo del término vero, cfr. Di Marzo, Salvatore, cit., (n. 26), p. 236; Arangio Ruiz, Vincenzo, cit. (n. 24), p. 153; y Harder, Manfred, cit. (n. 29) p. 525.

43 SAnfilippo, Cesare, cit. (n. 33), p. 566.

44 Gómez-Carbajo de Viedma, Fernando José, cit. (n. 17), p. 139. 
hipótesis el mandatario se obliga a construir un monumento funerario para después de la muerte del mandante. El cumplimiento de la prestación no podría serle exigido hasta después de la muerte del mandante, y por consiguiente parece que la obligatio, o al menos la actio dirigida a exigir su cumplimiento, nacería en la persona del heredero, lo que debería conllevar la nulidad del negocio en aplicación del precitado principio "obligatio ab heredis persona incipere non potest". Sin embargo, añade el A. que también es cierto que para la hipótesis de un mandato como el previsto en el texto examinado, salvo que se haya convenido otra cosa (es decir, si mediare pacto expreso de que el mandatario realice el encargo sua pecunia), el mandante está obligado a proporcionar al mandatario los medios necesarios para construir el monumento. Y si ello puede exigirse antes de la muerte del mandante, la obligatio, -o si se prefiere la actio- comenzaría en la persona del mandante, no en la de su heredero; y al no ser de aplicación la regla que debería determinar su nulidad, el mandato sería válido, y el heredero del mandante podría interponer la acción del mandato (actio mandati directa) contra el mandatario, en cualquier caso.

En relación al fragmento que examinamos (D. 17,1,12,17), indica en cambio José María Ribas Alba ${ }^{45}$ que el texto de Ulpiano no deja lugar a dudas sobre la posibilidad del mandato post mortem, y rechaza la opinión de aquellos autores que niegan esta figura recurriendo a la tesis de la modificación, al considerar que habría que leer en el texto: heres eius non poterit ${ }^{46}$.

Comparto la opinión de José María Ribas $\mathrm{Alba}^{47}$ de discrepar del parecer de Gómez-Carbajo de Viedma ${ }^{48}$, quien coloca como elemento determinante, para discernir sobre la nulidad o validez del mandato post mortem, la posibilidad o no por parte del mandatario de interponer la actio mandati contraria, en vida del mandante. Es preferible no establecer una estricta vinculación entre la admisibilidad de la institución del mandatum post mortem y la posibilidad por parte del mandatario de ejercitar la acción contraria, porque la viabilidad de este ejercicio dependerá de las circunstancias de cada caso: si el mandatario en un mandato post mortem no hubiese realizado ningún gasto, ni recibido ningún perjuicio en vida del causante, no habrá lugar al ejercicio de la actio contraria, pero sin que ello obste a la perfección del contrato de mandato.

2) Una paridad de criterio podemos encontrar en el fragmento que figura en el Digesto, inmediatamente a continuación, y que ha sido diversamente interpretado en la doctrina. El texto en cuestión es D. 17,1,13, "Gaius ad edictum provinciale: Idem est et si mandavi tibi, ut post mortem meam heredibus meis emeres fundum".

Para José María Ribas Alba ${ }^{49}$, por cuya opinión nos inclinamos con prefe-

45 Ribas Alba, José María, cit. (n. 17), p. 83.

${ }^{46}$ Cfr. Di Marzo, Salvatore, cit., (n. 26), p. 236; y la crítica que a la opinión de este último opone SANFILIPPO, Cesare, cit. (n. 33), pp. 566 ss.; también a la tesis del non se adhiere ARANGIO RuIz, Vincenzo, cit. (n. 24), p. 153. También defiende alteraciones textuales Voci, Pasquale, Diritto ereditario romano (2a ed., Milán, 1967), I, p. 267.

${ }^{47}$ Ribas Alba, José María, cit. (n, 17), ibíd.

${ }^{48}$ La opinión de Gómez-Carbajo de Viedma ya había sido esbozada por Arangio Ruiz, cit. (n. 24), pp. 155-156.

49 Ribas Alba, José María, cit. (n. 17), p. 84. 
rencia, en D. 17,1,13 estamos en presencia de un nuevo supuesto de mandato post mortem, que refuerza la interpretación que él mismo propone del fragmento anterior. La finalidad del encargo solo podrá ultimarse después de la muerte del mandante, sin que suponga una modificación de esta solución la posible anticipación de cantidades por parte del mandante o los posibles gastos desembolsados por el mandatario, también con anterioridad a la muerte del mandante, que le posibiliten el ejercicio de la acción contraria, por cuanto que el A. reconoce la admisibilidad de esta figura, incluso en la hipótesis de inactividad del mandatario con anterioridad al fallecimiento del mandante. La calificación de esta figura como mandatum post mortem ya había sido defendida también por Sanfilippo ${ }^{50}$, aunque se acepte la ubicación de este fragmento propuesta por Lenel ${ }^{51}$, quien hace preceder a D. 17,1,13 el pasaje de D. $17,1,27,1^{52}$.

3) También ha sido objeto de examen específico en relación a la materia que nos ocupa este último texto,-D. 17, 1, 27, 1, Gaius libro nono ad edictum provinciale - en el que se establece: "Si servum ea lege tibi tradidero, ut eum post mortem meam manumitteres, constitit obligatio: potest autem et in mea quoque persona agendi causa intervenire, veluti si paenitentia acta servum reciperare velim".

Rabie $^{53}$ con relación al D. 17,1,27,1 estima que estaríamos en presencia de una causa donationis con forma de mandatum post mortem, o bien de un mandatum acompañado de una cláusula referida a la muerte alterutrius contrahentis, que en este caso sería qui mandatum dedit. Y añade que el texto del D. 17,1,27,1 es claro en este punto: obligatio constituit, de suerte que tanto la cláusula como el mandato son válidos; mientras que en la hipótesis de D. 17,1,13 “il s'agit d'un véritable mandatum post mortem, non d'un mandatum établi pour dissimuler une donatio. "Estimamos tal vez más acertada la opinión de Gómez-Carbajo de Viedma ${ }^{54}$, para quien el supuesto contemplado en el fragmento 27,1 en ningún caso puede calificarse como un supuesto de mandatum post mortem como ha

50 Sanfilippo, Cesare, cit. (n. 33), p. 567.

51 Lenel, Otto, Palingenesia iuris civilis (Leipzig, 1889, reimpr. Graz, 1960), I, p. 214, n. 232 .

52 Esta discutida reconstrucción propuesta por Lenel presenta en nuestra opinión cierta verosimilitud por razón de su coherencia, si tomamos en consideración el contenido de los diversos textos (D. 17,12,17; D. 17,1,13; y D. 17,1,27,1). En este sentido, como ya indicó Gómez-Carbajo de Viedma, cfr. cit. (n. 17), p. 146, podría además pensarse que el texto de D. 17,1,27,1 comprensivo de dos afirmaciones, en la primera de las cuales se dice que constitit obligatio y en la segunda que potest autem et in mea quoque persona agendi causa intervenire, no es en su estructura muy distinto al transmitido en el fragmento 12,17 , porque "en última instancia, la primera mitad del texto corresponde a la sentencia de Marcelo y lo que se hace en la segunda es aducir exactamente la misma razón que adujo Ulpiano para justificar la afirmación de aquélla”. Sin embargo, la adopción de la decisión de Lenel tiene como inconveniente que en las correspondientes inscriptiones, el fragmento 13 se indica extraído del libro decimo, mientras que el 27 se afirma que procede del libro nono ad ed edictum provinciale, problemática a la que aluden el propio Gómez-Carbajo de Viedma, Fernando José, cit. (n. 17), p. 143, y Ribas Alba, José María, cit. (n. 17), p. 85.

53 RaBIE, Hamed A., L'acte juridique, cit. (n. 17), p. 290.

${ }^{54}$ Gómez-Carbajo de Viedma, Fernando José, cit. (n. 17), p. 144. 
defendido Zimmern ${ }^{55}$, así como Arangio-Ruiz ${ }^{56}$, porque la entrega o transmisión del esclavo se verifica en vida del mandante, por lo que no puede decirse que este muera re adhuc integra.

4) Comentaremos a continuación un texto de Gayo, cuya especial relevancia en esta materia ha sido destacada por Sanfilippo", Gai. 3,117: "Sponsores quidem et fidepromissores et fideiussores saepe solemus accipere, dum curamus, ut diligentius nobis cautum sit; adstipulatorem uero fere tunc solum adhibemus, cum ita stipulamur, ut aliquid post mortem nostram detur; quia enim ut ita nobis detur stipulando nibil agimus, adhibetur adstipulator, ut is post mortem nostram agat; qui si quid fuerit consecutus, de restituendo eo mandati iudicio heredi meo tenetur".

Sanfilippo defiende la existencia en el fragmento mencionado de dos mandatos diferenciados: uno inter vivos, ordinario, dirigido a realizar la adstipulatio; otro post mortem que consistiría en el encargo encomendado al adstipulator de hacer entrega al heredero del mandante de lo que hubiese podido conseguir a resultas de la adstipulatio concertada.

Sobre este particular en cambio, Gómez-Carbajo de Viedma ${ }^{58}$, que en este punto sigue las orientaciones de Arangio Ruiz ${ }^{59}$ y de Di Marzo ${ }^{60}$, considera que en esta hipótesis no estamos en presencia de un mandatum post mortem, al reconocer la existencia de un único mandato en el cual la adstipulatio ya se comenzó a ejecutar en vida del mandante, aunque el contrato solo pueda ultimar su cumplimiento después de fallecido el mandante, lo que a su parecer excluye la existencia de un mandatum de esta índole, respecto del cual únicamente se plantea el problema de su validez si el mandante ha fallecido re adhuc integra.

En relación a este punto estimo que conviene precisar, a los fines de determinar si estamos o no en presencia de un mandatum post mortem, si es más relevante el momento inicial en que tiene lugar la adstipulatio entre el mandante y el mandatario, o aquel en que el mandatario verifica la reclamación después del fallecido el mandante y en su caso, hace entrega de lo obtenido a los herederos del mandante. Y claramente me inclino, y en este punto coincido con J. M. Ribas Alba ${ }^{61}$, por la ostensible mayor relevancia del momento ulterior de reclamación y posterior entrega de lo conseguido en su caso a los herederos del mandante.

5) Para fundamentar la admisibilidad del instituto del mandatum post mortem en el derecho clásico se ha mencionado doctrinalmente la posibilidad reconocida en este derecho de acudir al propio testamento o a un codicilo como medio de encauzar un m.p.m. El contrato de mandato se perfeccionaría por la aceptación del encargo que el mandatario exteriorizaría con su propia actividad (facta concludentia $)^{62}$. En esta dirección Murga, sin llegar a reconocer la existencia del

\footnotetext{
${ }^{5}$ Apud Bonfante, Pietro, cit. (n. 23), p. 263 y Sanfilippo, Cesare, cit. (n. 33), p. 567, n. 46.

56 Gómez-Carbajo de Viedma, Fernando José, cit. (n. 17), pp. 155-156.

57 SAnfilippo, Cesare, cit. (n. 33), p. 564.

58 Cfr. Gómez-Carbajo de Viedma, Fernando José, cit. (n. 17), p. 162.

59 Cfr. Arangio Ruiz, Vincenzo, cit., (n. 24), p. 184.

${ }^{60}$ Cfr. Di Marzo, Salvatore, cit. (n. 26), p. 234.

61 Cfr. Ribas Alba, José María, cit. (n. 17), p. 86.

${ }^{62}$ Álvarez SuÁrez, Ursicino, El negocio jurídico en derecho romano, (Madrid, 1954), p. 16;
} 
mandatum post mortem en el derecho romano clásico, alude a unas posibles mandas piadosas o encargos in bonum animae ordenados por los testadores, al margen de los cauces habituales del derecho hereditario (legados y fideicomisos) y que parecen aproximarse a la noción del mandatum post mortem $^{63}$.

Analizando las fuentes se ha vislumbrado la posibilidad de un mandatum post mortem testamentario en el testamento de Dasumius Tuscus, redactado en el $108 \mathrm{~d}$. C., atribuido a P. Dasumio Tusco, cónsul en el 103, quien lo mandó reproducir en piedra en su tumba sita en la via Appia ${ }^{64}$, y por virtud del cual se designan curadores para encargarse de las exequias, de la construcción del sepulcro y de la continuidad de las ceremonias conmemorativas ${ }^{65}$; también en el conocido como testamento del Lingón ${ }^{66}$, habitante de la actual ciudad de Langres y que ha llegado hasta nosotros a través de una copia del siglo $\mathrm{X}^{67}$, en el que se alude al régimen de la cura funeris; así como en el testamento de Antonio Silvano, publicado en 1940 por Guéraud y Jouguet, y redactado en el 142, en el cual el testador nombra un procurator de sus bienes castrenses para que se haga con ellos y los entregue a Antonia Thermuta, madre de su heredero, a fin de que esta los conserve para su hijo heredero y se los transmita cuando este salga de la tutela ${ }^{68}$.

El reconocimiento del mandatum post mortem que formalmente se instrumentalice a través de un negocio testamentario parece entrar en contradicción con D. $11,7,14,2^{69}$, que posibilita el ejercicio de una actio de dolo contra la persona a la que el testador le hubiese encargado de su entierro, y que habiendo recibido el dinero, no hubiese dado cumplimiento al encargo, aunque esta dificultad puede solventarse, si como sostienen algunos autores, estimamos que en el supuesto examinado no estamos en presencia de un mandatum post mortem ${ }^{70}$.

BetTi, Emilio, Teoría general del negocio jurídico, (1943, trad. cast. Madrid, 1950, Granada, 2000), pp. 111 ss.

${ }_{63}$ Murga, José Luis, Donaciones y testamentos in bonum animae en el derecho romano tardío (Pamplona, 1968), pp. 166 ss.

${ }^{64}$ Cfr. CIL VI 10229; FIRA III, núm. 48.

${ }^{65}$ Castillo, Carmen, El famoso testamento del cordobés Dasumio, en Actas del I Congreso Andaluz de Estudios Clásicos (Jaén, 1981), pp. 159 ss.

${ }^{66}$ CIL XIII 5707; FIRA III núm.49.

${ }^{67}$ Cfr. Le Bohec, Yann, Le testament du Lingon (Lyon, 1991); RemesAl Rodríguez, José, In perpetuum dicitur. Un modelo de fundación en el Imperio Romano. Sex. Lulius Frontinus, lulius Sabinus» y el Testamento del Lingón (CIL XIII 5708), en Gerión, 13 (1995), pp. 99 ss.

${ }^{68}$ Para Ribas Alba el "receptor de estos encargos ratione mortis se configura sustancialmente como un ejecutor testamentario, porque según el A. un ejecutor, para serlo, no tiene por qué venir encargado del cumplimiento de todas las disposiciones testamentarias [en contra con matizaciones, se manifiesta AMELOTTI, Mario, Il testamento romano attraverso la prassi documentale (Firenze, 1966), p. 151]. Indica Ribas Alba [cfr. cit. (n. 17), p. 94] que una de las causas por las que suele excluirse al ejecutor deriva de la no admisión en el derecho clásico del mandatum post mortem, pero que admitido este, habría que concluir que el derecho romano conoció efectivamente la figura del ejecutor testamentario y que romanos son por tanto los fundamentos del albacea tal como aparece en el derecho medieval.

${ }^{69}$ D. 11,7,14,2, Ulpianus libro 25 ad edictum: "Si cui funeris sui curam testator mandaverit et ille accepta pecunia funus non duxerit, de dolo actionem in eum dandam Mela scripsit: credo tamen et extra ordinem eum a praetore compellendum funus ducere".

${ }^{70}$ Para WACKE, Andreas, Sul concetto di dolus nell'actio de dolo, en Iura, 28 (1977), p. 30, 
6) Finalmente, mencionaremos Paulus libro secundo manualium, D. 46,3,108: "Ei, qui mandatu meo post mortem meam stipulatus est, recte solvitur, quia talis est lex obligationis: ideoque etiam invito me recte ei solvitur. Ei autem, cui iussi debitorem meum post mortem meam solvere, non recte solvitur, quia mandatum morte dissolvitur".

Este es un texto que ha supuesto la base más sólida en que se han apoyado los detractores de la admisibilidad de este instituto en el derecho clásico. Ya desde antiguo ha propiciado la convicción en un amplio sector de la doctrina de la nulidad de la expresada figura jurídica y, en definitiva, la nulidad del negocio que nos ocupa ${ }^{71}$.

Sanfilippo ${ }^{72}$, con relación a los dos supuestos que contempla el fragmento precitado, estima que en el primer supuesto hay un doble mandato: uno inter vivos explícitamente mencionado, dirigido al mandatario para que verifique la estipulación y un segundo mandato implícito, post mortem; en el segundo supuesto, no nos encontraríamos ante un contrato de mandato, sino ante una hipótesis de delegación en la que el iussum conferido al deudor carece de eficacia fallecido el delegante.

Rabie $^{73}$ considera que el texto de Paulo no alude en modo alguno al mandatum post mortem. Interpreta el inciso: "Ei, qui mandatu meo [...] ei solvitur" estimando que en él Paulo acoge la regla general de que la muerte del mandante no determina la extinción de las relaciones contractuales entre el mandatario y los terceros $^{74}$. Y respecto del segundo inciso: "Ei autem, cui iussi debitorem meum post mortem meam solvere, non recte solvitur, quia mandatum morte dissolvitu”, niega

este fragmento demuestra la inexistencia del mandatum post mortem en el derecho clásico. Para C. SANFILIPPO [cfr. Ancora un caso di mandatum post mortem? en Sodalitas, Scritti in onore di Antonio Guarino (1984), V, pp. 2047 ss.], no estaríamos ante un mandatum post mortem, sino ante una disposición testamentaria innominada, por virtud de la cual el testador encomienda a una persona de confianza el hacerse cargo del funus. Sigue también esta dirección GómezCarbajo de Viedma, quien considera que esta hipótesis contemplada en el texto precitado nada tiene que ver con el mandatum post mortem [cfr. cit. (n. 17), p. 163] y también Ribas Alba [cfr. cit. (n. 17), p. 95] quien pone de relieve cómo en el texto precitado el testador realizó una oferta contractual en su testamento, que no consta que fuese aceptada por el destinatario, quien parece que se limitó a embolsarse el dinero, sin hacerse cargo del funus. En nuestra opinión, no es claro tampoco que estemos en presencia de un mandatum post mortem, por cuanto que el texto mencionado, lejos de aludir a una acción derivada del contrato de mandato, ejercitable por los herederos de quien hizo el encargo contra el destinatario del mismo, se hace en cambio referencia a una actio doli ejercitable contra este último.

${ }^{71}$ Sobre este texto Arangio Ruiz, cit. (n. 24), p. 152, afirma categóricamente: “Comunque, chi non ammetta per diritto classico la nullità del mandato post mortem mandatoris non potrà mai rendersi ragione del D. 46,3,108"; cfr. también GLÜCK, Cristiano Federico, Commentario alle Pandette XVII (tradotto ed annotato da Giovanni Pacchioni e Stanislao Cugia, Milano, 1904), p. 80.

${ }^{72}$ Cfr. Sanfilippo, Cesare, cit. (n. 33), p. 563.

73 Cfr. Rabie, Hamed A., L'acte juridique, cit. (n. 17), p. 255.

74 Cfr. ibíd., (n. 17), p. 278. Hablando de Paulo, Rabie señala: "Notre auteur commence par déclarer la règle générale, qui est la conséquence du caractère personnel, vinculum iuris, que revêt 'l'obligatio'. Les relations entre le mandataire et les tiers, c'est à dire les promettans, pour des stipulations conclues postérieurement, ne doivent en aucune façon subir une conséquence quelconque 
que se trate de una hipótesis de mandatum post mortem e incluso de un supuesto de delegatio, y considera que en él Paulo aporta una restricción a la regla general: la hipótesis de un iussum post mortem ${ }^{75}$.

Para Gómez-Carbajo de Viedma en el fragmento que nos ocupa se contemplan dos supuestos diferenciados, contraponiéndose por un lado el pago realizado en cumplimiento de una stipulatio, que a su vez se hubiese realizado en virtud de un mandato anterior, y, por otro, el efectuado en ejecución de un mandatum post mortem mandatoris. En relación al primer supuesto, el precitado A. se inclina por considerar que, en cumplimiento del mandato, el mandatario se ha hecho estipular en vida del mandante, pero para después de su muerte, el pago de una cantidad, entendiendo las palabras "mandatu meo post mortem meam stipulatus est" ${ }^{76}$, en el sentido de que, en cumplimiento del mandato y en vida del mandante, el mandatario ha celebrado una stipulatio sometida a un término consistente en la muerte del mandante ${ }^{77}$. Y añade el A. que, en tal hipótesis, la celebración de la stipulatio mencionada en el texto ha hecho nacer entre estipulante y promitente una obligación independiente, que se rige por la propia lex obligationis, contenida en las solemnes palabras pronunciadas y en cumplimiento de la cual el segundo paga válidamente al primero, de suerte que este primer supuesto no guarda relación alguna con el mandatum post mortem. En cambio, en la otra hipótesis que se plantea en el fragmento, sí que estaríamos claramente, según el A., ante un supuesto purísimo de "mandatum post mortem mandatoris exequendum".

Sin embargo, como ya pusieron de relieve Jens, Glück, Bonfante y Arangio Ruiz, entre otros, si en el segundo supuesto contemplado en el fragmento estuviésemos ante un mandatum post mortem mandatoris, el principio que debería haber determinado la extinción del contrato debiera ser el de "obligatio ab heredis persona incipere non potest" y no el que aquí parece tener aplicación, cual es el de la extinción del mandato por muerte de una de las partes. Por ello, si tomamos en consideración que el texto de este fragmento de interpretación compleja representa el mayor obstáculo para el reconocimiento de esta figura en el derecho clásico, estimamos muy comprensibles los esfuerzos realizados para defender que en el texto que examinamos no se alude al instituto del mandatum post mortem. Así es que pudiera ser admisible la solución ofrecida por $\mathrm{Cuyacio}^{78}$ quien defendía la siguiente transposición de los términos del fragmento que examinamos: " $E i$

à cause des relations entre le mandant et le mandataire. Si la mort met fin au mandat, cela concerne les relations entre le mandant et le mandataire, non les relations entre celui-ci et les tiers".

75 Cfr. ibíd., p. 279, n. 3: "[...] Dans la deuxième partie, il s'agit d'un cas particulier; le paiement n'est pas valable dans ce dernier cas, Paul insiste d'ailleurs sur ce caractère exceptionnel, en commençant par le mot 'autem'. La pensée de Paul peut être ainsi résumée: selon la règle générale, le paiement est valable, tandis qu'il en va tout autrement dans le cas du 'iussum post mortem' [...]".

${ }^{76}$ Aquí el A. (cfr. ibíd., p. 148) altera el orden de las palabras que figuran en el texto.

77 A juicio del A. (cfr. ibíd.) esta interpretación permite una explicación razonable de la posibilidad prevista en el propio texto de que el mandante intente oponerse-etiam invito mea que se realice el pago al mandatario-estipulante, lo que el A. entiende como un intento de revocación del mandato, oposición esta ineficaz por haberse celebrado ya la stipulatio.

${ }^{78}$ Cuiacius, Jacobus, Observationes et emendationes (Lyon, 1559), lib. I, cap. 38, cit. en GLÜCK, Cristiano Federico, cit. (n. 71), p. 81, n. 45. 
autem, cui iussi debitorem meum solvere, post mortem meam non recte solvitur, quia mandatum morte dissolvitur" 79 . De admitirse esta solución el texto trataría de un contrato de mandato ordinario.

Y más creíble que esta sería tal vez la posición que mantiene Ribas Alba ${ }^{80}$ quien opta por la hipótesis de que el texto de Paulo se refiere a diversos supuestos de delegatio. En la primera parte de D. 46,3,108 se contempla explícitamente la existencia de un mandato del delegante (acreedor) al delegado (deudor del primero como es el supuesto más habitual), y en virtud de este mandato, el delegado promete al delegatario. Una vez producida la delegación por medio de la stipulatio, Paulo destaca que ya no produce efectos un posible cambio de voluntad en el delegante. $\mathrm{Al}$ no establecerse expresamente ninguna indicación sobre la causa que ha llevado al delegante a poner en funcionamiento la delegación, estaríamos en presencia de un mandato ordinario, plenamente coherente con el texto que examinamos. $\mathrm{Y}$ en cuanto a la segunda parte del texto, estaríamos de nuevo ante un mandato ordinario, por cuanto que Paulo esgrime en este caso la regla de disolución del mandato por muerte de uno de los contratantes (en este caso del mandante) ${ }^{81}$.

2. Otras excepciones a la aplicabilidad de esta regla: exégesis de D. 17,1,26 pr.; D. 17,1,58pr.; I. 3,26(27), 10

Al margen de los textos examinados concernientes al instituto del mandatum post mortem, quedarían una serie de textos romanos que serían tal vez más próximos al contrato de mandato ordinario, por cuanto que no se indica explícitamente que el encargo deba ejecutarse después de la muerte, pero en los que sufre también alguna excepción el principio general mandatum morte solvitur. En efecto, a partir de la época clásica, las fuentes jurídicas recogen el principio de que el mandato se extingue por la muerte de cualquiera de las partes contratantes. Ello es así porque la base fundamental del contrato de mandato descansa en la plena y recíproca confianza de las partes, de suerte que con el fallecimiento de una de ellas cesa la

79 También B. 26,5,108 reproduce el texto en el orden indicado por Cuyacio.

${ }^{80}$ Cfr. Ribas Alba, José María, cit. (n. 17), p. 99.

81 Destaca Alonso, José Luis, El cobro de los créditos de la herencia yacente, en Labeo, 47 (2001), p. 214 que el pago a alguien distinto del acreedor (no importa si sometido a su potestad o extraño) solo libera si se realiza voluntate creditoris, o dicho de otro modo, el cobrador del crédito debe estar habilitado. El decaimiento de la habilitación para el cobro no afecta al deudor que lo ignora y para ilustrar este principio el A. trae a colación el supuesto n. 3 de Iulianus libro 13 digestorum D. 46,3,32: "[...] sicut is, qui iussus est a creditore pecuniam Titio solvere, quamvis creditor mortuus fuerit, nihilo minus recte Titio solvit, si modo ignoraverit creditorem mortuum esse." En este inciso final del texto de Juliano se indica que un acreedor dispone-iubet-que su deudor pague a un tal Ticio; aunque el acreedor muera, el deudor mientras lo ignore -si modo ignoraverit creditorem mortuum esse- seguirá pagando recte a Ticio. La razón por la cual el deudor solo se libera si ignora la muerte del acreedor iubens consiste en que la muerte del acreedor determina que Ticio deje de estar habilitado para el cobro. Y esto es así porque, cuando el acreedor muere, su voluntad, de la que el iussum solvendi es expresión, muere con él; la voluntas creditoris no es la suya, sino la de su heredero, sin cuya conformidad no se puede pagar válidamente a un tercero. El iussum solvendi se extingue por tanto con la muerte del iubens. La muerte tiene sobre el iussum el mismo efecto que la revocación y una aplicación de este principio se encuentra según el A. precisamente en D. 46,3,108. 
fiducia y el contrato se extingue ${ }^{82}$. Sin embargo, en algunos textos, que son precisamente aquellos, cuyo contenido, como veremos, refleja de una manera más directa el derecho de la recepción, se establecen excepciones al principio general de extinción del contrato por muerte de alguno de los contratantes. Entre ellos podríamos citar:

Paulus libro 32 ad edictum, D. 17,1,26 pr.: "Inter causas omittendi mandati etiam mors mandatoris est: nam mandatum solvitur morte. Si tamen per ignorantiam impletum est, competere actionem utilitatis causa dicitur. Iulianus quoque scripsit mandatoris morte solvi mandatum, sed obligationem aliquando durare" ${ }^{83}$.

Paulus libro quarto quaestionum, D. 17,1,58pr.: "Si praecedente mandato Titium defenderas quamvis mortuo eo, cum hoc ignorares, ego puto mandati actionem adversus heredem Titii competere, quia mandatum morte mandatoris, non etiam mandati actio solvitur. Quod si sine mandatu defensionem suscepisti, negotium quodammodo defuncti gerere institueras, et quemadmodum, si illum liberasses, competeret tibi negotiorum gestorum actio, ita potest dici et heredem eius eadem actione teneri's4.

I. 3,26(27),10: "Item si adhuc integro mandato mors alterutrius interveniat, id est vel eius qui mandaverit, vel eius qui mandatum susceperit, solvitur mandatum.

82 Sucede, en efecto, que la muerte del mandatario excluye toda posibilidad de ejecución del contrato por parte de la persona en quien el mandante depositó su confianza y sin que esta pueda ser transferida a los herederos del mandatario; análogamente, puede acontecer que, fallecido el mandante, sus herederos no depositen en el mandatario la misma confianza que le inspirase el causante; y por otra parte, es además cierto que el mandatario se había obligado a la conclusión de un negocio por voluntad del mandante, por lo que, fallecido este, desaparece o se diluye su voluntad. Cfr. Biondi, Biondo, Diritto ereditario romano. Parte generale (Milano, 1954), p. 104; cfr. también LóPEZ-RENDO, Carmen, Las causas particulares de extinción del mandato: de Roma al derecho moderno (Oviedo, 1999), p. 76.

${ }^{83}$ En el texto precitado Paulo indica la regla general que esbozamos al principio de nuestro trabajo de que el mandato se disuelve por la muerte -solvitur mandatum-, pero examina únicamente inter causas omittendi mandati la hipótesis de muerte del mandante -mors mandatoris-, exigiéndose para estimar disuelto el contrato que el mandatario tenga conocimiento de la muerte del mandante, por cuanto que, de ejecutar el encargo por ignorancia -si tamen per ignorantiam impletum est-, se reconoce la posibilidad de ejercitar la acción derivada del mandato utilitatis causa [Cfr. BIONDI, Biondo, cit. (n. 82), p. 104; ARANGIO RUIZ, Vincenzo, cit. (n. 24), p. 141; López-RENDo, Carmen, cit. (n. 82), p. 80]. Aunque Paulo en D. 17,1,26pr., a diferencia de Gayo (cfr. Gai, 3,160) no alude expresamente al requisito de que la muerte del mandante tenga lugar antes de que se ejecute el objeto del contrato de mandato-integro mandato-, para que se estime extinguido el contrato de mandato, la doctrina mayoritaria estima que también para este jurista tal exigencia era esencial. Así GLÜCK, Cristiano Federico cit. (n. 71), pp. 77 ss., indica que "si bien las leyes sientan el principio de que el mandato se extingue por la muerte del mandante, requieren sin embargo que se halle íntegro el mandato-integro adhuc mandato o re integra- de lo que se sigue en la hipótesis contraria, esto es, cuando la res ya no es integra, que la obligatio y la actio mandati quedan todavía vivas. Sobre la diversidad de posturas entre ambos juristas, Watson, Alan cit. (n. 29) pp. 129-131.

${ }^{84}$ Paulo en este texto aplica a la procuratio ad litem una regla similar a la contemplada en D. 17,1,26pr., fragmento también atribuido al propio jurista. En este texto se alude a un contrato de mandato cuyo objeto lo constituía la defensa de Ticio. Fallecido el mandante, ignorándolo el mandatario, este último da cumplimiento íntegro al mandato; y concluye Paulo que, si bien por la muerte del mandante se extingue el mandato, no así en cambio, la acción derivada del referido contrato. 
Sed utilitatis causa receptum est, si mortuo eo, qui tibi mandaverat, tu ignorans eum decessisse, executus fueris mandatum, posse te agere mandati actione; alioquin iusta et probabilis ignorantia tibi damnum afferet' ${ }^{\text {' } 5}$.

\section{EL DERECHO DE LA RECEPCIÓN}

La regulación del mandato durante la época visigoda está recogida principalmente en el Breviario de Alarico y en el Liber iudiciorum. Durante este período, el mandante aparece mencionado con el término de mandator, mientras que el mandatario se designa con las denominaciones de prosecutor, procurator, adsertor y mandatarius $^{86}$. El documento en el que se recoge el encargo recibe el nombre de iniunctio $^{87}$. Siguiendo la tendencia que se iniciaría en el Bajo Imperio se confunden las nociones de procura y mandato. El procurator se configura como un mandatario, que únicamente puede actuar en virtud de mandato previo. El cargo de procurator se desvaloriza socialmente y se considera torpe y deshonesto ${ }^{88}$.

$\mathrm{Y}$ en concreto en lo que concierne al tema que nos ocupa, nos interesa muy especialmente el libro II, título III, capítulo 8 del Liber iudiciorum, que lleva por rúbrica: De mandatoribus et mandatis, en el que no recibe regulación específica el mandatum post mortem, pero en cambio, sí que se contemplan algunas excepcio-

${ }^{85}$ Este texto tiene un contenido similar a Gai. 3,160, y en él se señala que el fallecimiento de cualquiera de las partes acaecido antes de ultimar la ejecución del encargo - "item si adhuc integro mandato mors alterutrius interveniat" - disuelve el mandato -solvitur mandatum, atribuyendo una actio mandati al mandatario que, desconociendo la muerte del mandante, ejecute el encargo-, "tu ignorans eum decessisse, executus fueris mandatum, posse te agere mandati actione". En I. 3,26(27), 10 y en Gai. 3,160 se utilizan los mismos términos sed utilitatis causa receptum est y se justifica la concesión de la actio mandati por razón de utilitas, por cuanto que de otro modo -alioquin- iusta et probabilis ignorantia tibi damnum afferet. ORTOLAN, Joseph Louis Elzéar, [cfr. Explicación histórica de las Instituciones del Emperador Justiniano: con el texto, la traducción al frente y las explicaciones debajo de cada párrafo, precedida de la historia de la legislación romana, desde su origen hasta la legislación moderna, y de una generalización del derecho romano, según los textos conocidos antiguamente ó más recientemente descubiertos, (5 $5^{\mathrm{a}} \mathrm{ed}$. rev. y aum. por Francisco Pérez De Anaya y Melquíades Pérez Rivas, Madrid, 1884), p. 361], con respecto a la expresión iusta et probabilis ignorantia, señala que combinado este texto con D. 17,1,27,3, a diferencia de la hipótesis de fallecimiento del mandante, después de fallecido el mandatario, los herederos de este último al ejecutar el mandato no pueden ejercitar la acción derivada de este contrato, porque no pueden ignorar el fallecimiento de la persona a quien suceden, y no hay para ellos iusta et probabilis ignorantia.

${ }^{86} \mathrm{La}$ voz de mandatarius aparece inicialmente en Occidente en una ley de Chindasvinto [cfr. Pérez Martín, Antonio, Mandato y representación en el derecho histórico en Anales de Derecho, 12 (Murcia, 1994), p. 221], aunque el término en cuestión parece que era conocido en Oriente ya en el siglo VI [cfr. LevY, Ernst, Weströmisches Vulgarrecht. Das Obligationenrecht (Weimar, 1956), pp. 69-70].

${ }^{87}$ En las llamadas Fórmulas Visigóticas se alude a tres fórmulas de iniunctiones: una para litigar, otra para reclamar una deuda, y una tercera para recuperar un siervo, Cfr. Pérez MarTín, Antonio, cit. (n. 86), p. 222; Martín Minguez, Bernardino, Las llamadas Fórmulas Visigóticas (Madrid, 1920), cit. por A. Pérez Martín.

${ }^{88} \mathrm{Y}$, en consecuencia, se prohíbe el cargo de procurator a obispos, presbíteros y diáconos, cfr. LEVY, Ernst, cit. (n. 86), p. 63. 
nes a la regla mandatum morte dissolvitur: "Qui mandatum fecit, si mortuus fuerit antequam causa dicatur, mandatum quod fecerat non valeat; et qui mandatum suscepit, si antequam causa dicatur, fuerit morte praeventus, mandatum nullam habeat firmitatem. Quod si antequam moreretur causam dixisse dinoscitur, atque per suam instantiam ad fines usque legitimos perduxerit, et tamen quocumque casu intercedente, nec dum perfinita res, aut exacta remansit, si ad hunc forte terminum fuerit causa deducta, quo eam ille qui per mandatum sequutus est, iam ante acceleraverat, omne lucrum quod ipse fuerat habiturus, haeredibus eius a mandatoris partibus exsolvatur'89.

El mandato se extingue, entre otras causas, por muerte del mandatario, quien transmite sus derechos a los herederos ${ }^{90}$. También se extingue por muerte del mandante, si esta tuviese lugar antes de que el mandatario principie su gestión ${ }^{91}$.

La terminología que se emplea en el Fuero Juzgo, versión romance del Liber iudiciorum, encuentra su justificación en la concepción procesal del mandato a que hemos aludido. En ella, al igual que en el Liber iudiciorum, encontramos nuevamente excepciones al principio mandatum morte dissolvitur. El título III del libro II lleva por rúbrica: De los mandadores e de las cosas que mandan ${ }^{92}$. Y su capítulo 8 bajo el título: Del que es personero, si muriere, sus herederos deven aver lo quel fuera prometido dispone: "El que tiene personero en el pleyto, si se muriere, ante que el pleyto sea acabado, el mandado que fizo al personero non vala nada ${ }^{33}$. E si el personero muere por aventura ante que el pleyto sea acabado, el mandado otrosí non vala nada ${ }^{94}$. E si el pleyto era acabado ante que él muriese, é por algun empiezo por ventura el sennor del pleyto non avie aun recibida la cosa quel era juzgada, si la cosa avinier á aquel plazo que el personero fiziera que fuesse pagada, sus herederos del personero deven aver el precio quel fuera prometido daquel que lo metió por personero, ó de sus parientes, ó de sus herederos ${ }^{5}$ ".

${ }^{89}$ En relación a este texto señala PaCheco Caballero, Francisco, La recepción de la doctrina del mandato en las Partidas, en Revista de Derecho Privado, 74 (1990), pp. 658 ss., que, a pesar de la rúbrica, las leyes incluidas en el título mencionado aluden en exclusiva al mandato procesal, lo que implica la pérdida de la noción del mandatum como contrato. Y añade el A. que cuando se utiliza el término mandatum, con el expresado concepto se alude al poder otorgado para litigar y representar a otro en juicio o al instrumento mismo en que el poder ha sido escrito.

${ }^{90}$ Así parece desprenderse de la frase que encabeza el capítulo 8, libro II, título III del Liber iudiciorum (LV, 2,3,8: "Ut si mortuus fuerit is qui mandatum accipit, commodum illi debitum haeredes eius accipiant").

${ }^{91}$ Parece que resulta así de los términos: "Qui mandatum fecit [...] habeat firmitatem".

${ }^{92}$ La edición manejada es la de Fuero Juzgo en latín y castellano, cotejado con los más antiguos y preciosos códices por la Real Academia Española, publicado por Ibarra, Impresor de Cámara de S.M. Madrid, 1815.

${ }^{93}$ En esta primera hipótesis se contempla la posibilidad de extinción de la personería como consecuencia de la muerte del que encargó efectuar la gestión, antes de que el pleyto haya acabado.

${ }^{44}$ En este segundo supuesto se señala que también desaparece el mandato si fallece el personero, con anterioridad a que el pleyto haya finalizado.

${ }^{95}$ En este último caso, en el texto parece indicarse que, si terminó el pleyto antes de que falleciese el personero, y el sennor del pleyto no hubiese aún recibido lo que le corresponde, aunque la cosa, es decir, el asunto se hubiese ejecutado dentro del plazo mencionado, los herederos del personero tienen derecho a percibir el pago del precio prometido por el sennor del pleyto, el cual pueden reclamar de los parientes o herederos del sennor. 
Benito Gutiérrez considera que los "fueros municipales aparecen mudos" con respecto al mandato, institución que debió de regirse por la costumbre, ya que "documentos antiguos acreditan su existencia" ${ }^{96}$. En sentido similar se manifiesta Pacheco Caballero, al indicar que la búsqueda de noticias sobre el contrato de mandato es infructuosa en los fueros municipales, al igual que en el Fuero Real. Si bien el Liber aún conservaba cierta terminología y regulaba algunos aspectos, que nos ponían en conexión con la idea del mandatum; el Fuero Real, en cambio, lo mismo que hiciera el Fuero Juzgo, rompe con todas las ataduras que, aunque solo terminológicas, permitían ligar al Liber con la tradición romana del mandato ${ }^{97}$. Y así el Fuero Real habla siempre del dueño de la voz para referirse a lo que antes era el mandator o qui mandatum fecit. Se emplea el término personero para aludir a lo que antes era el adsertor, prosecutor o mandatarius. El propio término de mandatum empleado en el Liber para designar el poder o el instrumento escrito en el que consta el poder recibe la denominación en el Fuero Real de personería o de carta de personería.

El Fuero Real alude a la figura del personero, circunscrita a la hipótesis del procurador judicial en el libro I, título X, bajo la rúbrica "De los personeros" y en la ley XVIII de este mismo título se contempla la hipótesis de muerte, tanto del dueño de la voz, como del personero" ${ }^{98}$ : "Si alguno diere personero en algun pleito $e$ ante que el personero entre en la voz con el contendor, muriere el dueño de la voz quel dio por personero, tal personería non vala mas ${ }^{99}$. Et si en voz entró ante que el dueño de la voz muriese, todo lo que fue fecho por tal personería vala, e pueda traer el pleito fasta que gelo tuelga aquel a quien pertenesce el pleito por razon del muerto, si el pleito fue ante comenzado por respuesta asi como manda la ley ${ }^{100}$. Otrosi si el personero muriere ante que entre en la voz, la personería non vala: et si en voz entró ante que muriese, vala aquello que fizo, e sus herederos hayan el galardon que él habia de haber segunt lo que merecía ${ }^{101}$.

En las Partidas no encontramos un título autónomo dedicado al mandato y se produce la separación entre dos instituciones diferenciadas: a) por un lado se contempla en el título XII, Partida V, leyes 20 y siguientes una reglamentación

\footnotetext{
${ }^{96}$ Cfr. GutiérRez Fernández, Benito, Los Códigos o estudios fundamentales sobre el derecho civil español, tratado de las obligaciones, (Madrid, 1869), IV, p. 501.

${ }_{97}$ Pacheco Caballero, Francisco, cit., (n. 89), p. 660.

${ }^{98}$ La edición que utilizamos es la de Opúsculos legales del Rey Don Alfonso El Sabio, publicados y cotejados con varios códices antiguos por la Real academia de la Historia (Madrid, 1836), II.

${ }_{99}$ Este primer inciso parece acoger el principio de que, si falleciese el dueño de la voz, antes de la ejecución del encargo procesal por el personero, el mandato se extingue.

${ }^{100}$ De este texto parece desprenderse que, si el pleito o encargo se había ya iniciado antes de que muriese el dueño de la voz, será válido todo lo efectuado por el personero antes de la muerte del dueño de la voz, y puede continuar las gestiones correspondientes a ese pleito hasta que le sustituya el heredero de quien le designó como personero, que es a quien ha de pertenecer el pleito después del fallecimiento del decuius.

${ }^{101}$ Finalmente, si el personero falleciese antes de iniciar el encargo, la personería se extingue; mientras que si se dio comienzo al pleito antes de morir el personero tiene validez todo lo realizado por él hasta entonces, pudiendo los herederos del personero percibir lo que a este último hubiese correspondido por su intervención.
} 
de esta figura que se articula a través de la consideración de la misma como " $m a$ nera de obligación semejante de la fiadura", ubicándose, en consecuencia, junto a las normas de la fianza, aun cuando solo algunos de los originarios supuestos de mandato romano podrían considerarse próximos a esta figura de garantía personal $^{102}$ y b) por otra parte, la Partida III, título V se refiere al mandato judicial bajo la rúbrica "De los personeros".

La Partida III, título V, ley XXIII, bajo la rúbrica "Quando se acaba el officio del Personero" contempla la extinción del oficio del personero por muerte de las partes: "Muriendose el señor del pleyto, ante que su Personero lo començasse por demanda e por respuesta, acabase porende el officio del Personero, de guisa que non puede, nin deue despues yr adelante por el pleyto ${ }^{103}$. Mas si se muriese despues que fuesse començado por respuesta, non pierde por esso el Personero su poderio; ante dezimos, que deue seguir el pleyto, fasta que sea acabado, tambien como si fuesse biuo el que lo fizo Personero; maguer non recibiesse mandado nueuamente de los herederos del finado ${ }^{104}$. E otrosi dezimos, que si el Personero se muere, ante que el pleyto sea començado por respuesta, que se acaba el officio del. Mas si muriesse despues que lo ouiesse començado, sus herederos del deuen, e pueden acabar lo que el començo, si son hombres para ello ${ }^{105}$ ".

Pacheco Caballero estima que no es posible afirmar con total certidumbre que los redactores de las Partidas estimasen suficiente, en lo que concierne a la extinción del mandato, lo anteriormente indicado con relación a la personería. Constata sin embargo que la ausencia de esta materia en el texto alfonsino no pudo deberse a la ausencia de un modelo, por cuanto que las causas de extinción estaban desarrolladas in extenso en las fuentes justinianeas utilizadas por las Partidas ${ }^{106}$.

Si bien en las Partidas no se contempla el instituto del mandato post mortem, sí que se regula en ellas, como una de las modalidades de la promissio, la promissio post mortem en la Partida V, título XI, ley XII en los siguientes términos: "E aun dezimos, que podría prometer uv ome a otro, de dar o de fazer alguna cosa, ante que finasse, a días contados, o después, como si dixesse: Prometo de dar o fazer tal cosa diez días ante que fine o después. E por tal promission como esta fincan otrosi obligados sus herederos, e son tenudos de la cumplir [...]".

102 Cfr. Arcos Vieira, Ma Luisa, Sobre el contrato de mandato en el código civil y en el Fuero Nuevo, en Revista Jurídica de Navarra, 22 (1996) pp. 61-86.

103 Cfr. Las Siete partidas del sabio rey Don Alonso el Nono; glosadas por el licenciado Gregorio Lopez; del Consejo Real de Indias de su S.M., II, (Madrid, 1843-1844), p. 90 (n. 1), en la que con referencia a la ley XIII se indica que la expresión "muriendose” concuerda con la de Item si $a d h u c$ con la que principia I. 3,26,10. En este texto se señala que, si el señor del pleito fallece antes de que el personero principie el pleito, se extingue el oficio del personero, quien en lo sucesivo no puede seguir en adelante con el pleito.

${ }^{104}$ Si el fallecimiento del señor del pleito tuviese lugar después de que el personero hubiese contestado a la demanda, dicho personero debe proseguir el pleito hasta su finalización, aunque para ello no hubiese recibido nuevo mandato de los herederos del finado.

105 Se extingue la personería si el fallecimiento del personero tiene lugar antes de que comience el pleito; si en cambio el personero fallece después de iniciado el pleito, sus herederos tienen la obligación de acabar lo que aquél comenzó, si fuesen capaces de ello.

106 Pacheco Caballero, Francisco, cit. (n. 89), p. 670. 
Parece que no es posible encontrar disposiciones en las que las actuaciones de las partes se asemejen al contrato de mandato, ni en el Ordenamiento de Alcalá de 1348, ni en el Ordenamiento de Montalvo de 1484, ni en las leyes de Toro de 1505. Únicamente en las Ordenanzas de Bilbao de 1737 se regularía el mandato mercantil, que con posterioridad contemplaría el Código de Comercio.

\section{AnÁlisis de la cuestión en el Código Civil español}

\section{Las excepciones a la regla mandatum morte dissolvitur en el Código Civil}

El artículo 1732 apartado $3^{\circ}$ del Código Civil español en su redacción de 1889 disponía que el mandato se acaba por la muerte del mandante o del mandatario ${ }^{107}$. El mencionado cuerpo normativo dedica a esta particular causa de extinción y sus efectos los siguientes preceptos:

Artículo 1718: "El mandatario queda obligado por la aceptación a cumplir el mandato, y responde de los daños y perjuicios que, de no ejecutarlo, se ocasionen al mandante. Debe también acabar el negocio que ya estuviese comenzado al morir el mandante, si hubiere peligro en la tardanza ${ }^{108 "}$.

Artículo 1738: "Lo hecho por el mandatario, ignorando la muerte del mandante $u$ otra cualquiera de las causas que hacen cesar el mandato, es válido y surtirá todos sus efectos respecto a los terceros que hayan contratado con él de buena fe."

$\mathrm{Y}$ el artículo 1739: "En el caso de morir el mandatario, deberán sus herederos ponerlo en conocimiento del mandante y proveer entretanto a lo que las circunstancias exijan en interés de éste".

Los artículos 1738 y 1739 representan respectivamente una reproducción casi literal de los correlativos $1628^{109}$ y $1629^{110}$ del Proyecto de 1851.

${ }^{107}$ La actual redacción de este precepto dada por el artículo 11 de la ley 41/2003, de 18 de noviembre, de protección patrimonial de las personas con discapacidad y de modificación del Código Civil entre otras disposiciones, no afectó en modo alguno al extremo que nos ocupa.

108 Este artículo tiene su precedente en el artículo 1609 del Proyecto de 1851 que establece: "El mandatario queda obligado por la aceptacion á cumplir el mandato, y responde de los daños y perjuicios que, de no ejecutarlo, se ocasionen al mandante. Debe tambien acabar el negocio comenzado ya al morir el mandante, si hubiere peligro en la tardanza". Según García Goyena, este precepto es concordante con I. 3,27,11; D. 17,1,5,1; D. 17,1,27,2 y D. 17,1,5,1. Con relación al Derecho castellano, cita la Partida III, titulo 12, ley 21: "Si rescibiese el mandato dévese trabajar de cumplirlo quanto pudiere bien é lealmente". Cfr. GARCÍA GOYENA, Florencio, Concordancias, motivos y comentarios del Código Civil español (Madrid 1852), IV, pp. 40-41.

109 El artículo 1628 de las Concordancias establecía: "Lo hecho por el mandatario, ignorando la muerte del mandante ú otra cualquiera de las causas que hacen cesar el mandato, es válido, y surtirá ademas todos sus efectos, respecto de los terceros que hayan contratado de buena fé". Con relación a este precepto señala GaRCía GoYena, cit. (n. 108), p. 56, que "En el caso de este artículo el mandatario obra de buena fé y en utilidad de solo el mandante. Asi, aunque atendido el rigor de derecho, no debia valer lo obrado por el mandatario despues de la cesacion del mandato, se admitió lo contrario ex bono et aequo, que en contratos de esta especie debe prevalecer sobre los ápices del derecho. Los terceros se encuentran en el mismo caso que el mandatario cuando, como él, obran de buena fé: si obran de mala fé sabiendo, por ejemplo, la muerte del mandante, aunque la ignorase el mandatario, no podrán prevalerse de lo hecho".

${ }^{110}$ La redacción del precedente artículo 1629 del Proyecto era la siguiente: "En el caso de morir el mandatario deberán sus herederos ponerlo en noticia del mandante, y proveer entretanto á 
El artículo 1628 del Proyecto de 1851 tiene a su vez un claro precedente, en opinión de García Goyena ${ }^{111}$, en Paulus libro 32 ad edictum, D. 17,1,26pr., en Paulus libro quarto quaestionum, D. 17,1,58pr., así como también en Instituciones 3,26(27), 10 .

En los artículos mencionados del Código Civil no se contempla explícitamente la admisibilidad del mandatum post mortem, por cuanto que no se alude en ninguno de ellos a la posibilidad de que el contenido del mandato deba ejecutarse con posterioridad a la muerte del mandante o del mandatario, pero sí que se reconocen claras excepciones al principio mandatum morte solvitur. Al igual que sucedía en el derecho romano, el Código Civil español parece atribuir efectos diversos a la muerte de cualquiera de los contratantes, según que esta acontezca antes de comenzar la ejecución del encargo objeto del mandato, o bien durante la ejecución del mismo:

a) Si la muerte del mandante o mandatario tuviese lugar integro adhuc mandato y fuese conocida por ambas partes, se extingue el mandato sin producir efecto alguno. Los efectos de la muerte se producen ex tunc, quedando privados los herederos de cualquiera de las partes de la posibilidad de ejercitar acción alguna derivada del contrato de mandato. Así lo estima la doctrina mayoritaria considerando que a esta conclusión nos lleva el artículo 1732, que con carácter general establece, sin precisar exigencia alguna, que el mandato se acaba por la muerte del mandante o del mandatario, y de la interpretación a contrario sensu de los artículos 1718, 1738 y 1739 del Código Civil.

b) De no concurrir el requisito de la res integra, por haber iniciado el mandatario la ejecución del encargo, los efectos serán diversos para las hipótesis de muerte del mandante o del mandatario:

b.1) Para la hipótesis de muerte del mandante, una vez acaecida esta, puede suceder que el mandatario no haya iniciado la ejecución del mandato, pero que al llegar a su conocimiento el fallecimiento del mandante, aquel haya cumplido íntegramente con la obligación que aceptó en su día en vida de este; o bien que la muerte del mandante acontezca iniciada que fuere su obligación por parte del mandatario, pero sin haberla ultimado, de suerte que, desconociendo la muerte del mandante persevere en la gestión del mandato, y que al tener noticia del fallecimiento del mandante, el mandatario haya íntegramente cumplido con su obligación. Para ambos supuestos, la solución es la que propone el Código Civil en el precitado artículo 1738.

En dicho precepto podemos distinguir entre los efectos que se producen en

lo que las circunstancias exijan para interes del mismo". En relación a este precepto señala García Goyena: "El mandante escogió la probidad é industria del mandatario; su confianza fué personal: por otra parte, el mandatario se decidió á admitir su encargo por cariño tambien personal hacia el mandante: debe, pues, espirar el mandato por la muerte del mandatario. Pero el deber que aqui se impone á sus herederos, se funda en que el velar sobre la conservacion de la cosa, que era objeto del mandato, es una carga de la herencia, pues que se deriva esencialmente de la obligacion originaria contraida por el difunto mandatario". Cfr. cit. (n. 93), pp. 56-57.

111 García GoYena, Florencio, cit. (n. 108), p. 56. 
las relaciones internas entre mandante y mandatario y los que se producen frente a terceros.

i) con respecto a los efectos en las relaciones internas, podemos indicar que, dado que la muerte del mandante extingue el contrato de mandato, stricto iure, en principio todo lo realizado por el mandatario después de la muerte del mandante carecería de eficacia frente a los herederos del mandante. Excepcionalmente, sin embargo, el artículo 1738 mitiga este particular efecto, reconociendo la validez de lo ejecutado por el mandatario que ignorase la muerte del mandante. Manresa señala que la norma establecida por el artículo 1738 constituye una excepción a los principios generales, que se encuentra justificada por los principios de equidad, para evitar que el summum ius represente la summa iniuria ${ }^{112}$. Scaevola considera que en el caso de litigio es al mandante o a sus herederos a quienes incumbe probar que el mandatario conocía o debía conocer el hecho que puso fin al mandato ${ }^{113}$. La ignorancia, como causa de excepción a la extinción del mandato, será de hecho valorada por los tribunales, con sujeción a las pruebas objetivas existentes, como se desprende de la Sentencia de 29 de septiembre de 1975.

Parece que la solución adoptada aquí por el Código Civil se aproxima a la ofrecida por los textos romanos que pretendieron amparar la posición del mandatario, ignorante de la muerte de su mandante, concediéndole la posibilidad de ejercitar una actio mandati contraria, siquiera utilis, contra los herederos del mandante ${ }^{114}$.

ii) con relación a los efectos respecto de terceros, como consecuencia del respeto debido a la buena fe, si los terceros desconociesen la muerte del mandante, los actos que realizasen de conformidad con el encargo serán válidos y producirán todos sus efectos en aplicación del artículo 1738 del Código Civil. Si la ignorancia concurriese en el mandatario y en los terceros que contratasen con él, el negocio realizado por el mandatario sería plenamente eficaz y, acreditada la buena fe, el mandatario quedaría exento de toda responsabilidad personal en aplicación del artículo 1725 del Código Civil ${ }^{115}$. Para la hipótesis de que concurriese ignorancia en los terceros y conocimiento de la muerte en el mandatario, han sido varias las posturas mantenidas por la doctrina. Para Manresa, en el caso de que la mala fe radicara en el mandatario y no en los terceros, aquel sería responsable del dolo y podrían estos ejercitar contra él las correspondientes acciones ${ }^{116}$. Para Gordillo Cañas, la buena fe del tercero, sobre la base firme de la apariencia, es fundamento suficiente para su protección, sin que se precise la concurrencia de ningún otro

${ }^{112}$ Manresa, José María, Comentarios al Código Civil español (Madrid, 1950), XI, pp. 574 ss.

113 Scaevola, Quintus Mucius, Código Civil comentado y concordado extensamente (Madrid, 1951), XXVI, p. 983.

${ }^{114}$ Cfr. Gai. 3,160; D. 17,26,pr.; D. 17,1,58,pr.; I. 3,26,10. Suscribimos en este punto la opinión manifestada por C. LópEz-RENDO, cit. (n. 82), p. 236; cfr. también sobre esta temática RODRÍgUez LóPEz, Rosalía, Las excepciones a la regla mandatum morte solvitur en la tradición jurídica española, en Actas del II Congreso Iberoamericano de Derecho Romano (Murcia, 1998), pp. 389 ss.

115 Manresa, José María, cit. (n. 112), p. 562; De La Cámara Álvarez, Manuel, La revocación del mandato y del poder, en Anales de la Academia Matritense del Notariado, 4 (Madrid, 1948), p. 649.

${ }^{116}$ Manresa, José María, cit. (n. 112), p. 562. 
requisito. El fundamento del artículo 1738 no se asienta en la equidad, sino en la apariencia jurídica, orientada en esencia a la protección de los terceros ajenos al contrato de mandato existente.

En esta misma orientación, Espejo Lerdo De Tejada ${ }^{117}$, estima con relación a la STS, 1a , 13.2.2014 que la opción interpretativa sostenida por la misma "supone un duro golpe para la idea, trabajosamente elaborada por nuestra mejor doctrina y la jurisprudencia, de que es necesario proteger a los terceros de buena fe, cuando inculpablemente confían en una apariencia objetiva de representación generada por los actos del mandante, o producida en su ámbito de riesgo, y concurra o no la buena fe del tercero con la del representante". También señala el A. muy acertadamente que debe rectificarse la letra del art. 1738 del Código Civil en un sentido protector del tercero de buena fe. La insuficiente formulación literal del art. 1738 del Código Civil debe integrarse con la disposición del art. 1734 del Código Civil, que no supedita la protección del tercero de buena fe a la existencia de esa misma buena fe en el mandatario.

Para la hipótesis de que el fallecimiento del mandante tenga lugar, iniciada que fuere la ejecución del mandato por parte del mandatario, sin que este hubiere cumplido íntegramente el mandato cuando llegare a su conocimiento la muerte del mandante, la doctrina mayoritariamente suele estimar que de nuevo tiene aplicación el artículo 1738, de suerte que tiene reconocida validez todo lo realizado por el mandatario que ignorase la muerte del mandante. Y finalmente, la regla contemplada en el artículo 1732 en su relación con el 1738 conoce la excepción a la que se alude en el artículo 1718, en virtud de la cual si hubiere peligro en la tardanza, el mandatario debe también acabar el negocio comenzado al morir el mandante, de suerte que, excepcionalmente, concurriendo esta causa, no se extingue el contrato de mandato.

b.2) Para el supuesto de muerte del mandatario, la solución adoptada por el derecho romano si dicho fallecimiento se produjere antes de haber empezado a cumplir el mandato es la de extinción del contrato de mandato, de suerte que el heredero del mandatario no queda obligado a continuar el encargo objeto del contrato, y de ejecutarse el mandato, el heredero carece de acción contra el mandante o sus herederos ${ }^{118}$.

En el derecho español, en cambio, el artículo 1739 del Código Civil establece dos obligaciones a cargo de los herederos del mandatario: 1) poner en conocimiento del mandante la muerte del mandatario; y 2) proveer entretanto a lo que las circunstancias exijan en interés de este.

Para Albaladejo García ${ }^{119}$, el deber de los herederos de continuar las cuestiones en curso al tiempo de fallecer su causante no permite atribuir a dicha continua-

117 Espejo Lerdo De Tejada, Manuel, La interpretación literal del art. 1738 CC y la representación aparente. A propósito de algunas Sentencias recientes del Tribunal Supremo, en InDret, Revista para el análisis del derecho, (Barcelona, 2015), pp. 8 ss. Visible en internet: www. indret.com/pdf/1119 es.pdf.

118 Cfr. D. 17,1,27,3.

119 Albaladejo García, Manuel, La representación, en Anuario de Derecho Civil, 11 (1958), pp. 790 ss. 
ción un carácter representativo, sino que se trata solo de gestiones derivadas de la anterior representación, aunque es pensable que, en algunos supuestos, estas hayan de desarrollarse mediante la realización de un nuevo negocio en nombre y cuenta del representado, lo que daría lugar realmente a un poder de representación conferido ex lege con carácter provisional. Y añade el A. que, realmente, si la necesidad fue el impulso necesario para el establecimiento legal de tal poder, la urgencia en la previsión de lo estrictamente necesario debe ser el límite racional de la obligación impuesta a los mandatarios.

Para la aplicabilidad del artículo 1739 del Código Civil se exigirían los siguientes presupuestos:

1) Conocimiento de la muerte del mandatario por parte de sus herederos. Albacar López y otros ${ }^{120}$ indican que, dado que este traslado de gestión a los herederos del mandatario no constituye un supuesto de adquisición de derechos y deberes ex iure proprio, y sí en cambio ex iure creditoris, la responsabilidad por los daños y perjuicios que de la actuación de los herederos pudiera sobrevenir al mandante no surge en tanto no tuvieran conocimiento del fallecimiento de su causante, así como de la existencia del contrato de mandato.

2) Conocimiento por los herederos del mandatario del contrato de mandato existente entre el mandante y su causante. Señala Scaevola que quedan liberados de ambas obligaciones contempladas en el artículo 1739 los herederos del mandatario que ignorasen la existencia del contrato de mandato entre su causante y el mandante ${ }^{121} ; y$

3) Capacidad de los herederos para asumir el negocio comenzado por su causante. Para Pérez González y Alguer, en su caso, y aunque no se trate de una solución positiva extraída de la normativa legal, también deben considerarse obligadas las personas que a su vez fuesen responsables de la representación, guarda y tutela de los herederos del mandatario ${ }^{122}$.

León Alonso indica finalmente que, además de las obligaciones que directamente dimanan del artículo 1739, han de tomarse en consideración aquellas otras obligaciones y derechos derivados de la relación contractual, transmisibles mortis causa por el mandatario a sus herederos ${ }^{123}$, tales como la obligación de rendir cuentas a la que en su momento no pudo dar cumplimiento el causante, justificando las gestiones verificadas y las que quedaren pendientes, y además, de acuerdo con lo establecido en el artículo 1726 en su relación con el artículo 1739, los herederos del mandatario deberán asumir el pago de las indemnizaciones debidas al mandante por los daños y perjuicios ocasionados no solamente por el dolo, sino también por la culpa de su causante.

${ }^{120}$ Albacar López, José Luis - Santos briz, Jaime - Martín Granizo Jaime, y Albiez Dohrmann, Klaus Jochen, Código civil. Doctrina y jurisprudencia (Madrid, 1991), p. 396.

121 Scaevola, Quintus Mucius, cit. (n. 113), p. 1003.

122 Pérez González, Blas y Alguer, José, Notas al Enneccerus, Derecho Civil, Parte General (Madrid, 1950), II, p. 347.

123 León Alonso, José R., Artículos 1909 a 1739 del Código Civil, Comentarios al Código Civil y Compilaciones Forales (dir. M. Albaladejo) (Madrid, 1986), pp. 606-607. 


\section{2. ¿Es admisible el mandatum post mortem en el derecho civil español?}

La mayoría de los civilistas españoles contemporáneos estiman con relación al mandato post mortem, considerando como tal aquel mandato cuyo objeto hubiese de ejecutarse después de la muerte del mandante o del mandatario, que la figura adecuada para esa finalidad sería el albaceazgo, y no el mandato. En este sentido, en la resolución de la Dirección General de los Registros y Notariado de 16 de noviembre de 2000, se indicó que "la muerte del poderdante es causa de la extinción del poder (artículo 1.732.3 del Código Civil), y aunque puede ocurrir que del poder extinguido derive algún efecto posterior (artículo 1.738 del Código Civil), ello es distinto al mandatum post mortem, que carece de regulación en el Código Civil, ya que los encargos para después de la muerte son contemplados en dicho cuerpo legal a través de figuras distintas del propio mandato".

No obstante, la Ley 559 de la Compilación del Derecho Civil Foral de Navarra admite expresamente la figura que nos ocupa ${ }^{124}$.

La doctrina española ${ }^{125}$ pone de relieve, sin embargo, que en determinadas ocasiones el contrato de mandato se puede utilizar por el futuro causante para encargar al mandatario la realización de una determinada prestación tras la muerte del mandante. En el tratamiento actual de esta materia sería posible la distinción entre las siguientes clases o mandatos post mortem:

1) En primer término, sería posible pensar en los casos planteados por las fuentes romanas: se encarga al mandatario construir un monumento, comprar un fundo para los herederos etc., es decir, lo que Albaladejo denomina "mandato precisamente conferido para ejecutar algo para después de la muerte ${ }^{126}$. La validez de este debe rechazarse por cuanto que la figura apropiada para llevar a cabo estos cometidos es el albaceazgo.

No han faltado en efecto autores que han hablado de "mandato especial" o de "mandato post mortem de carácter especial" al aludir al albaceazgo. Y así para Díez Picazo, y Gullón ${ }^{127}$ no cabe duda de que el albacea es, en un sentido muy amplio, gestor de intereses ajenos y por eso es acertada en líneas generales la posición de aproximarlo al mandatario. En nuestra jurisprudencia, de una forma expresa o implícita, se da a entender que el albacea es un mandatario del testador, aunque se reconozca incidentalmente que esta tesis no es enteramente correcta (sentencia

${ }^{124}$ En efecto, en el Anteproyecto y el Proyecto de Fuero Recopilado de Navarra, textos cuyo contenido es prácticamente idéntico y claramente inspirado en el derecho romano, se admitiría la validez del mandato post-mortem (leyes 146 y 148). En la actualidad, parece reconocer la expresada figura la ley 559 del Fuero Nuevo de Navarra que dispone: "El mandato se extingue por la muerte del mandante o del mandatario. El mandatario queda obligado a cumplir el encargo que se le encomendó para después de morir el mandante".

125 Cfr. en este sentido, Espejo Lerdo De Tejada, Manuel, La sucesión contractual en el Código Civil (Sevilla, 1999), pp. 111 ss.

${ }^{126}$ Albaladejo, Manuel, Derecho civil (Barcelona, 1982), II/2º, p. 331. El A. cita la sentencia del TS de 3 de junio de 1950, que rechazó la validez de un mandato otorgado para realizar la partición de la propia herencia, fundamentándose este fallo en la aseveración de que el mandato se extingue con la muerte.

127 Díez Picazo, Luis y Gullón, Antonio, Sistema de derecho civil (7a ed., Madrid, 2001), III, p. 397. 
de 18 de diciembre de 1959). En efecto, no lo es en tanto la designación del albacea es producto de un acto jurídico unilateral post mortem, no de un mandato propiamente dicho, ya que no estamos en presencia de un contrato, como es el mandato. El albacea, si acepta el cargo, no responde a la eventual oferta que se le hiciera, pues no se hace en vida del oferente, en aplicación del artículo 1262 del Código Civil. El punto de contacto que tiene con la figura del mandato es la relación de confianza con el testador. Esta equiparación al mandato permite, no obstante, y así lo ha hecho la jurisprudencia del Tribunal supremo, aplicar la normativa jurídica de esta institución para suplir las lagunas que presenta la regulación del albaceazgo en el Código Civil.

2) En segundo lugar podríamos hablar del mandato conferido para que el mandatario concluya con otra persona el contrato de donación. Con relación a este supuesto, Lacruz ya señaló que "aunque se admitiera -aun contra la postura doctrinal mayoritaria- que es posible el mandatum post mortem, existirían trabas insalvables para reconocer su validez, cuando su finalidad fuese conferir una liberalidad, pues el poder o el mandato en sí no son actos de atribución patrimonial; y consistiendo el encargo en una liberalidad, es evidente, ya la falta de vinculación anterior del donante, que pudo en cualquier momento revocar las instrucciones, ya la imposibilidad de aceptar la donación en vida del donante cuando, por definición, al ejecutar el mandato este ha fallecido ${ }^{128 "}$.

3) Cabría también la posibilidad de que el mandatario hubiese recibido ante mortem la propiedad de las cosas que el donante pretende que adquiera un tercero. Este sería el único supuesto en que, según León Castro, quedaría fundamentada la utilidad del mandatum post mortem, por cuanto que "los bienes han sido transferidos al ejecutor de la voluntad del fallecido con anterioridad a su muerte" con el encargo de transferirlos a la muerte del donante, a una tercera persona ${ }^{129 "}$.

4) Por último, podríamos aludir al supuesto de donación pactada entre el donante-mandante y el donatario, pero cuya ejecución se hubiese aplazado a la muerte del donante, encomendándose al mandatario la entrega al donatario de la cosa donada. En tal hipótesis, habría que considerar que puesto que el mandato supone la ejecución de un contrato válido debería también admitirse su validez y su irrevocabilidad para los herederos del mandante ${ }^{130}$.

Finalmente indicaremos que la jurisprudencia española, desde antiguo, ha admitido en condiciones excepcionales la validez de lo que denomina un mandato

${ }^{128}$ Compartimos en este punto la opinión de Albaladejo de estimar que el mandato en sí no representa un acto de atribución patrimonial y si bien es cierto que la concurrencia de voluntades entre donante y donatario solo la exige el artículo 633 del Código Civil con relación a los bienes inmuebles, la mayor parte de la doctrina estima que en la donación de bienes muebles dicho requisito debe estimarse implícito en la ley. Cfr. Albaladejo, Manuel, Comentarios al Código Civil y compilaciones forales (Madrid, 1986), VIII/1º, pp. 185-186).

${ }_{129}$ Aunque como señala el A. si la figura tiene utilidad en realidad es porque en este supuesto nos encontraríamos en una hipótesis de donación modal, excluida del ámbito del mandato. Cfr. León-Castro, José, Comentarios al Código Civil y compilaciones forales (Madrid, 1986), $\mathrm{XXI} / 2^{\circ}$, pp. 522 ss.

${ }_{130}$ Albiez Dohrmann, Klaus Joechen, Negocios atributivos post mortem (Barcelona, 1998), p. 198. 
post mortem, contemplando la posibilidad de que un mandato pueda subsistir tras la muerte del mandante, en los mismos casos en los que considera irrevocable el mandato ${ }^{131}$, esto es, cuando su celebración no sea expresión de la mera confianza o se base en el simple interés del mandante, sino que responda a exigencias de cumplimiento de otro contrato en el que estén interesados, no solo el mandante, sino también el mandatario o terceras personas. En tal sentido se orienta STS 30 septiembre 1975 en la que se indica que, con carácter general, la "extinción del mandato se produce por muerte del mandante"; sin embargo, en el supuesto enjuiciado, el Tribunal consideró que la muerte del mandante no determinó la extinción del poder dado para llevar a cabo una partición hereditaria; y ello, basándose en que dicho mandato se fundamentaba, no en "la conveniencia o interés exclusivo del mandante, sino que obedecía a exigencias de otro contrato, y por lo mismo había de subsistir, mientras subsista el contrato originario que motivó el otorgamiento del poder".

\section{BiBLIOGRAFÍA}

Albacar López, José Luis - Santos Briz, Jaime - Martín Granizo Jaime y Albiez Dohrmann, Klaus Jochen, Código Civil. Doctrina y jurisprudencia (Madrid, 1991). Albaladejo García, Manuel, La representación, en Anuario de Derecho Civil, 11 (1958), pp. 767 ss.

-- Derecho civil, (Barcelona, 1982), II/2º.

Albaladejo García, Manuel (dir.), Comentarios al Código Civily Compilaciones Forales (Madrid, 1986).

Albiez Dohrmann, Klaus Joechen, Negocios atributivos post mortem (Barcelona, 1998). Alonso, José Luis, El cobro de los créditos de la herencia yacente en Labeo, 47 (2001), pp. 210 ss.

ÁlVAREZ SuÁrez, Ursicino, El negocio jurídico en derecho romano (Madrid, 1954). Aмеlотті, Mario, Il testamento romano attraverso la prassi documentale (Firenze, 1966). Arangio Ruiz, Vincenzo, Il mandato in diritto romano (1949, reimp., Napoli, 1965). Arcos Vieira, Ma Luisa, Sobre el contrato de mandato en el Código Civil y en el Fuero Nuevo, en Revista Jurídica de Navarra, 22 (1996), pp. 61-86.

Betтi, Emilio, Teoría general del negocio jurídico (1943, trad. cast. por A. Martín Pérez, Madrid, 1950, reimp. Granada, 2000).

Biondi, Biondo, Diritto ereditario romano. Parte generale (Milano, 1954).

Bonfante, Pietro, Mandatum post mortem, en Scritti giuridici varii (Turín, 1926), III, pp. 262 ss.

Castillo, Carmen, El famoso testamento del cordobés Dasumio, en Actas del I Congreso Andaluz de Estudios Clásicos (Jaén, 1981), pp. 159 ss.

De la Cámara Álvarez, Manuel, La revocación del mandato y del poder, en Anales de la Academia Matritense del Notariado, 4 (Madrid, 1948), pp. 551 ss.

De Verda, y Beamonte, José Ramón y Escrivá Terán, Enrique José, Breve estudio

${ }^{131}$ Cfr. De Verda y Beamonte, José Ramón y Escrivá Terán, Enrique José, Breve estudio de la extinción del mandato desde un punto de vista jurisprudencial, en Actualidad Juridica Iberoamericana 2, (febrero 2015), pp. 517 ss. 
de la extinción del mandato desde un punto de vista jurisprudencial, en Actualidad Jurídica Iberoamericana, 2 (febrero 2015), pp. 517 ss.

Díez Picazo, Luis, y Gullón, Antonio, Sistema de derecho civil (7a ed., Madrid, 2001), III.

Di MARzo, Salvatore, Sul mandato post mortem, en Scritti Ferrini, 1 (1947), pp. 233 $-238$.

Di PaOla, Santi, L'atto giuridico post mortem, en Labeo, 1 (1955), pp. 342 ss.

Domingo, Rafael (coord.) - Ortega, Javier - RodrígueZ-Antolín, Beatriz - Zambrana, Nicolás, Principios de derecho global. 1000 reglas y aforismos jurídicos comentados ( $2^{\text {a }}$ edición, Cizur Menor, 2006), pp. 265 ss.

Espejo Lerdo De Tejada, Manuel, La sucesión contractual en el Código Civil (Sevilla, 1999).

-- La interpretación literal del art. 1738 CC y la representación aparente. A propósito de algunas Sentencias recientes del Tribunal Supremo, en InDret, Revista para el análisis del derecho, (Barcelona, 2015), pp. 8 ss.

García Goyena, Florencio, Concordancias, motivos y comentarios del Código Civil español (Madrid 1852), IV.

GLÜCK, Cristiano Federico, Commentario alle Pandette (tradotto ed annotato da Giovanni Pacchioni e Stanislao Cugia., Milano, 1904), XVII.

Gomez-Carbajo de Viedma, Fernando José, Mandatum post mortem, en Revista de la Facultad de Derecho Universidad Complutense, (1989-1990), pp. 129 ss.

GuTIÉRREZ FERnÁNDEZ, Benito, Los códigos o estudios fundamentales sobre el derecho civil español, tratado de las obligaciones (Madrid, 1869), IV.

HARDER, Manfred, Zum transmortalen und postmortalen Auftrag nach römischen und geltendem Recht, en Sein und Werden im Recht. Festgabe für Ulrich von Lübtow zum, 70 (Berlin, 1970), pp. 515-536.

Jordano BAREA, Juan Bautista, Teoría general del testamento, en Anales de la Universidad Hispalense, 24 (Sevilla, 1963), pp. 61-93.

LE BoHec, Yann, Le testament du Lingon (Lyon, 1991).

Lenel, Otto, Palingenesia iuris civilis (Leipzig 1889 - reimpr. Graz, 1960), I.

LEVY, Ernst, Weströmisches Vulgarrecht. Das Obligationenrecht (Weimar, 1956).

LOPEZ-RENDO, Carmen, Las causas particulares de extinción del mandato: de Roma al derecho moderno (Oviedo, 1999).

LotMar, Philipp, Marc Aurels Erlass über die Freilassungsauflage, en ZSS., 33 (1912), pp. 304 ss.

Manresa, José María, Comentarios al Código Civil español (Madrid, 1950), XI.

Murga, José Luis, Donaciones y testamentos in bonum animae en el derecho romano tardio (Pamplona, 1968).

Ortolan, M., Explicación histórica de las Instituciones del Emperador Justiniano: con el texto, la traducción al frente y las explicaciones debajo de cada párrafo, precedida de la historia de la legislación romana, desde su origen hasta la legislación moderna, $y$ de una generalización del derecho romano, según los textos conocidos antiguamente ó más recientemente descubiertos, (5a ed. rev. y aum. por Francisco Pérez De Anaya y Melquíades Pérez Rivas, Madrid, 1884).

Pacheco Caballero, Francisco, La recepción de la doctrina del mandato en las Partidas, en Revista de Derecho Privado, 74 (1990), pp. 658 ss.,

Pérez González, Blas y Alguer, José, Notas al Enneccerus. Derecho civil. Parte general (Madrid, 1950) II. 
Pérez Martín, Antonio, Mandato y representación en el derecho histórico, en Anales de Derecho, 12 (1994), pp. 205 ss.

Pernice, Alfred, Labeo: Römisches Privatrecht im ersten Jahrhundert der Kaiserzeit (Halle, 1892; reimp. Aalen, 1963), III/1º, pp. 129 ss.

Perozzi, Silvio, Istituzioni di diritto romano (2a ed., Milano, 1928), II.

RABIE, Hamed A., L'acte juridique post mortem en droit romain: Validité et fonction (Milano, 1955).

-- L'atto giuridico post mortem, en Labeo, 3 (1957), pp. 92 ss.

-- "D.46,3,108», en Studi Arangio Ruiz (Napoli, 1953), IV, pp. 263 ss.

Remesal Rodríguez, José, In perpetuum dicitur. Un modelo de fundación en el Imperio Romano. Sex. Lulius Frontinus, lulius Sabinus» y el Testamento del Lingón (CIL XIII 5708), en Gerión, 13 (1995) pp. 99 ss.

Ribas Alba, José María, Mandatum post mortem, en Seminarios Complutenses de D. romano (2002), XIV, pp. 57 ss.

RODRíguez LÓPEZ, Rosalía, Las excepciones a la regla mandatum morte solvitur en la tradición jurídica española, en Actas del II Congreso Iberoamericano de Derecho Romano (Murcia, 1998), pp. 389 ss.

Sanfilippo, Cesare, Mandatum post mortem, en Studi Solazzi (Napoli, 1948), pp. 554 y ss.

SANFilippo, Cesare, Ancora un caso di mandatum post mortem?, en Sodalitas, Scritti in onort di Antonio Guarino (1984), V, pp. 2047 ss.

SCAEvola, Quintus Mucius, Código Civil comentado y concordado extensamente (Madrid, 1951), XXVI.

Solazzi, Siro, Sull'obbligazzione a termine iniziale, en Iura, I (1950), pp. 50 ss.

Torrent, Armando, Diccionario de derecho romano (Madrid, 2005),

Van Oven, Julius Christiaan, Gaius 3. 158: mandatum post mortem mandantis, en Symbolae Raphaeli Taubenschlag, 1 (1956), pp. 529 ss.

VASAlli, Filippo E., Di talune clausole con riferimento al "dies mortis" nel legato e nella stipulazione (Firenze, 1910).

VÀZNY, Jan, Il problema generale dei contratti a favore di terzi nel diritto romano, en BIDR., 40 (1932), pp. 79 ss.

VocI, Pasquale, Diritto ereditario romano (2a ed., Milano, 1967).

WACKE, Andreas, Sul concetto di dolus nell'actio de dolo, en Iura, 28 (1977), pp. 10 ss.

Watson, Alan, Contract of mandate in Roman law (Oxford, 1961). 